\title{
10 Vibrant Venice: Designing with Vibrant Matter
}

I have also thought of a model city from which I deduce all the others ... It is a city made only of exceptions, exclusions, incongruities, contradictions. If such a city is the most improbable, by reducing the number of abnormal elements, we increase the probability that the city really exists. (Calvino, 1997, p.69)

\subsection{Overview}

This chapter speculatively explores how the principles of vibrant matter may be applied to an urban-scale project. Specifically, it proposes to empower the city of Venice with lifelike abilities that enable it to engage in a struggle for survival against the elements - just like living things do! 'Vibrant Venice' was initiated in February 2009, as a model system that proposed to couple the synthetic activity of artificial and natural systems within the lagoon to grow an artificial limestone reef under the city. The project is a multidisciplinary collaboration that combines speculative fiction, empirical science, fieldwork and architectural design. A particular kind of ELT was conceived for this project, based on dynamic oil droplets that are light sensitive and can produce an accretion material using resources in the lagoon system. The sinking of Venice into the soft delta soils on which it is founded is offset by the accretion of an artificial reef around the woodpiles, which spread the point load of the city over a much broader base. This project has been developed in collaboration with Neil Spiller and Martin Hanczyc, with drawings produced by working with Christian Kerrigan and GMJ. Vibrant Venice is not just a speculative proposition, but has been supported by field tests that are based on scientific research, which is at an early stage of development. The project proposes how vibrant matter may be applied through ELT across different scales of operation, and raises questions about how humans and non-humans may begin to codesign their environment and evolve their shared environmental future.

\subsection{Future-proofing Architecture}

In spite of our inability to accurately predict the future, we are rather good at surviving it. When I say 'we', I mean 'life' as we know it. Early life forms are likely to have been extinguished many times by violent asteroid showers before they finally established themselves on the Earth's surface some 3.5 billion years ago (Whitehouse, 1999). The surface of the planet is not kind or constant. It is a far from equilibrium system that requires a lot of energy for any structure to persist on its surface. After all, when considering the geological timescales that life has endured, even mountains are moved.

In 1609, Galileo was in Venice when he heard of an invention called the telescope, which allowed distant objects to be seen as distinctly as if they were nearby (Sis, 
2000). By looking up, using this instrument, Galileo expanded the similarity between Earth and all the other heavenly bodies (Latour, 2013), setting the precedent for other Enlightenment thinkers to attempt to erase ambiguity from our world, using the principles of classical science. Indeed, such 'natural laws' propose that our existence is deterministic, so that it is possible to predict 'future scenarios' if we know the present location, properties and trajectories of all atoms in the universe (Prigogine, 1997, p.22).

Modern buildings embody Enlightenment scientific thinking, since they are constructed using engineering principles. Yet, over the course of the 20th century, it has become increasingly clear that equilibrium-state mechanical solutions cannot match the computational processes within natural systems. In many ways, classical machines are built as if in opposition to Nature. While looking down on us from one of those heavenly bodies, James Lovelock actually decreased our similarity with the heavenly bodies that Galileo had observed and challenged the unique attributes of the Earth (Latour, 2013). While mechanical systems simplify the laws of existence through 'natural law', natural systems themselves recomplexify events through many parallel processing systems. Ultimately, these give rise to acts of succession by the elements, bacteria, seedlings and other life forms. Indeed, the computational power of the chemistry underpinning such natural technologies is so powerful that nothing is spared this process. Consequently, machines and architectures are inevitably assimilated back into the shifting material systems of the Earth - sometimes on geological timescales, through the incessant, tiny acts of (re)complexification. Occasionally these changes take place much more rapidly during 'natural disasters', when Earth's forces act extremely and unpredictably around tipping points.

Modern buildings, which are both built by and imagined as machines (Gallagher, 2001; Le Corbusier, 2007, p.158), require significant investment in energy and resources for maintenance if they are to resist the relentless non-linear calculations of the material world. This results in significant wear and tear of inert materials, which occurs at the many microenvironmental interfaces in which our buildings are immersed. Viewed over a 30-year period, we spend 1-2\% per annum of the initial construction costs of a building on maintenance (CBEC and APEGBC, 2009). However, these expenditures are manageable and economically justifiable when social and environmental conditions are stable.

Yet, fuelled by anthropogenic causes, the natural world appears to be increasingly restless, as recent catastrophic events testify: in New York City with hurricane Sandy (Bloomberg, not dated), in New Orleans with hurricane Irene (Dolnick, 2011), the Sendai tsunami in Japan (NBC News, 2012) and the loss of lives in flash floods in the UK (Telegraph, 2013). While we have always lived in a probabilistic world, it is becoming increasingly obvious that our global environmental system is reaching multiple environmental tipping points. While we have laws and models that can help us deal with non-linearity, the processes that underpin phase changes in material behaviour remain mysterious. Indeed, it is apparent that, over the course of this century, our 
environment will not be predictable or stable, and the way that we imagine and design architecture is simply not designed to deal with this degree of ambiguity or change.

With the advent of software and high-speed computer processing, it is possible to imagine and visualize urban environments as complex systems, or ecologies, whose trajectories are probabilistic - not deterministic. Probabilistic solutions are based in 'general systems theory' (Von Bertalanffy, 1950; Von Bertalanffy, 1969) and require a different approach in constructing an idea of the future. They address an emergent, contingent series of events that are shaped by their relationship to an unevenly distributed and constantly changing present. This does not mean that 'anything goes', since all events exist within finite limits of possibility. However, the decision pathways and events that shape the outcomes remain open to influence by many contingencies until they have actually occurred. So, although the trade-off for a probabilistic future is certainty, the creative potential is increased and outcomes can be continually shaped (Prigogine, 1997).

These probabilistic trajectories are better expressed as algorithms. Although software programs are used to inform architecture, such as in the practice of parametrics (Schumacher, 2009) where lively relationships are viewed through computer visualization, the underlying dynamic principles cannot be embodied in the production of architecture, since traditional architectural materials are selected and designed to perform at equilibrium states. Yet, Stuart Kauffman questions the conventional notion of equilibrium, noting that within the lifetime of the universe the composition of molecules can alter indefinitely (Kauffman, 2008, p.125). Nevertheless, the classical concept of equilibrium, where no (effective) net energy enters or leaves a system, applies in the case of design, where objects are assumed to be inert and possess no internal capacity to change or initiate events. In contrast, non-linear systems continually absorb and release energy, which confers them with dynamic properties that change throughout the design process. There is, therefore, a pressing need to establish ways of embodying flexibility, robustness and creativity within a portfolio of design solutions, so that architects can work with materials that can deal with non-linearity at far from equilibrium states. Such vibrant materials may provide contingency and produce outcomes that can deal with the eventuality of reaching tipping points in natural systems.

Yet a completely different set of approaches to the mechanical solutions that we are most familiar with exists, which deals with constant change as an inherent aspect of its organization. Life itself may be thought of as a kind of analogue computer, which resists the decay towards entropic equilibrium (Schrödinger, 1944) and is enabled to do so by the incredible parallel processing powers of chemical systems. These draw on the properties of the quantum world, which govern their molecular interactions and physical properties. ${ }^{60}$ Matter, therefore, uses quantum computing techniques, which

60 Deutsch observes that all physical processes are quantum-mechanical and that quantum computing is a distinctively new way of harnessing Nature (Deutsch, 1997, pp.194-195). 
confer it with robustness, flexibility and capacity to deal with unpredictable events, by being engaged in continually unfolding chemical events, which are separated through space and time (Deutsch, 1997, p.194).

Indeed, Nature has been shown to behave according to non-locality, which is inconsistent with a system that operates according to quantum theory (Popescu, 2006; Pawlowski et al, 2009). In Rhythmanalysis (Lefebvre, 2004), Lefebvre begins to imagine how dynamic networks of vibrations, a macroscale version of string theory where extended bodies, or waves, permeate the fabric of our cities and forge everyday existence. ${ }^{61}$ Lefebvre's ideas of connecting rhythms are embodied with real effects that are experienced at many levels, such as sounds in the air, the motivating force of our circadian biology and as expressions of chemical periodic activity.

\subsection{Venice as a Case Study for Urban-Scale Design with Vibrant Matter}

The future of Venice in northern Italy has always been precarious, being tethered to the shoreline, which is arguably the most ferocious environment on Earth. It is situated on the shores of a lagoon where the Po delta meets the Adriatic Sea (see Figs. 10.1-10.4).

The landscape is changeable and geographically ephemeral, being continually shaped by opposing forces of land and sea. Gradually, the historic architecture is beginning to lose its battle with the non-human world, being constantly battered by the elements, repeatedly flooded, desiccated, biologically (re)assimilated and chemically digested. The city itself is continually being remodelled by the exchanges between its various actants, where biology, architecture, machines, people and their effluents forge networks of interactions. These chemical networks lay down the substrates upon which the next group of assemblages exert their effects. In this way, old systems are not destroyed and replaced by new ones; they continue to exist and be transformed by new layers that wrap themselves around each other, merge with their predecessors, or erode and dissipate to be redistributed elsewhere in the lagoon. Venice itself could be thought of as the result of a process of architectural succession ${ }^{62}$ facilitated by incessant material shifts, which transforms the city over time.

In biological terms, succession is a natural process where metabolisms

61 String theory, or 'superstring theory', is where extended objects, 'strings', rather than point-like particles, form the elementary building blocks of matter (Deutsch, 1997, p.23).

62 Allan Savory defines biological sustainability as 'roughly biology's answer to entropy - a thrusting up as opposed to a running down, the irrepressible striving of living communities to become more dynamic diverse and stable. This is the force that causes jungles to overgrow old civilizations in areas of perennial rainfall, and soils to form from lava flows. It is the process that provided the biological capital we now use and which maintains the air we breathe' (Savory, 1991). 


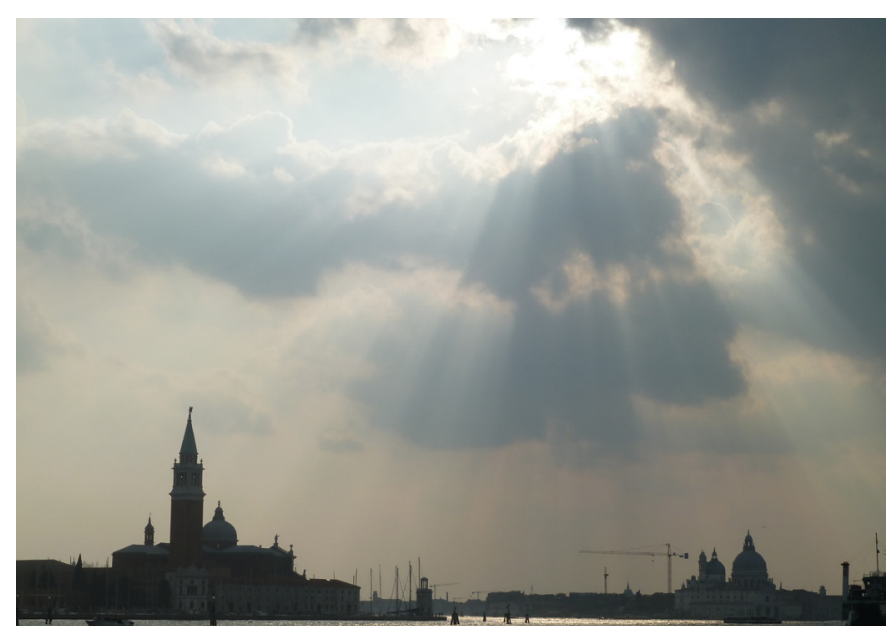

Figure 10.1: This view of Venice across the lagoon towards the Grand Canal (right) depicts the rich elemental infrastructure in which the city is immersed. The continual flow of matter through the site contributes to the battering of its architectural fabric, owing to the restless elements, but also nurtures the dense growth of biological systems in the waterways. Photograph, Rachel Armstrong, August 2010.

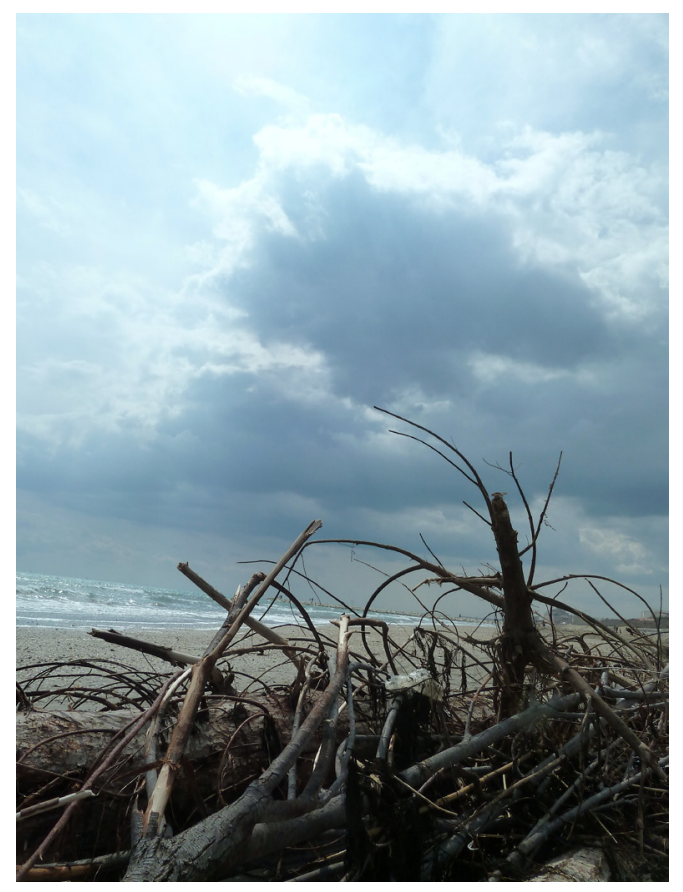

Figure 10.2: Jetsam on the shores of the Lido on the Adriatic Sea includes debris from trees that form a fence-like assemblage and garbage from the Venetian lagoon. Photograph, Rachel Armstrong, August 2010. 


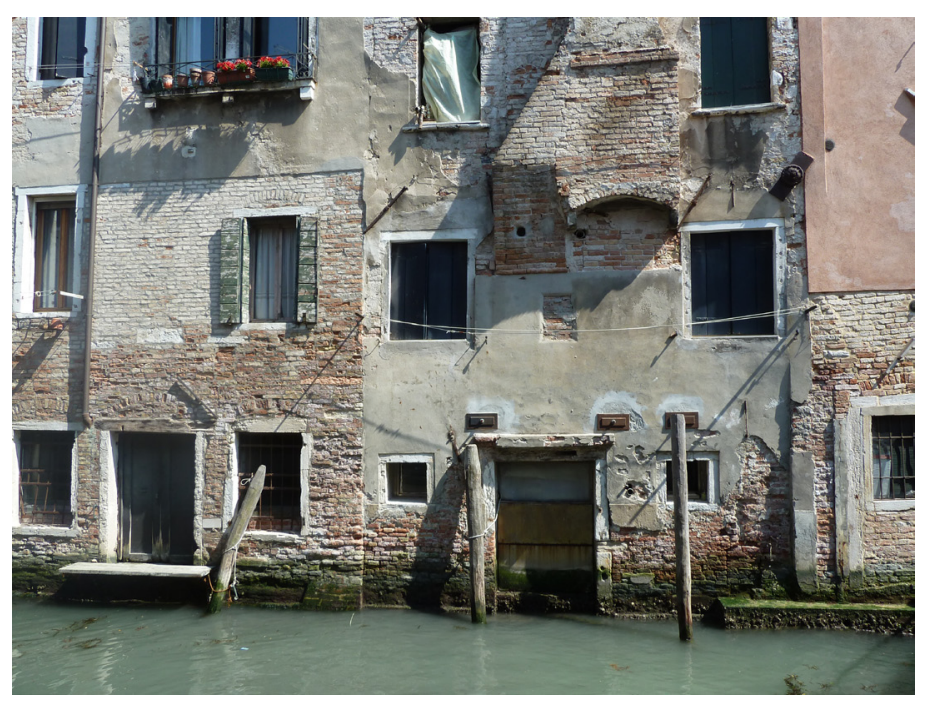

Figure 10.3: The continual morphological computing processes of the elements and marine organisms have weathered these Venetian buildings. Natural forces operate on the fabric of Venetian buildings in complex ways, such as brickwork being digested, generating a coating of white salt or efflorescence. Photograph, Rachel Armstrong, August 2010.

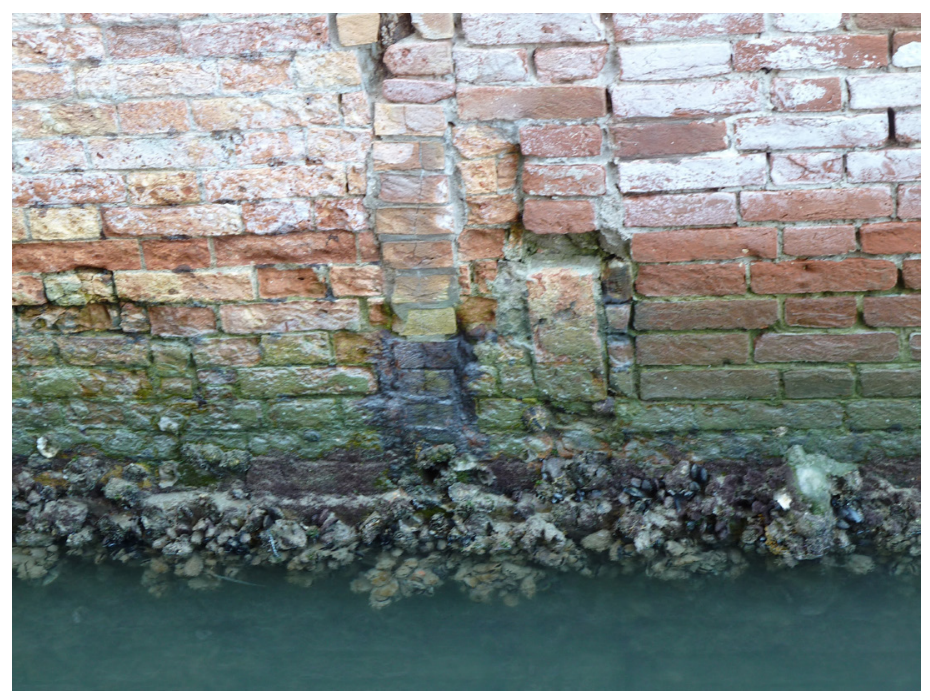

Figure 10.4: Physical processes act in concert with the local organisms like oysters, algae, bacteria and mussels, and produce metabolic events that shape the architectural fabric of Venetian buildings. These entanglements of natural and man-made materials constitute a post-natural building fabric, which functions as a vertical synthetic marine ecology at the tideline. This process may be likened to the production of scar tissue in an organism. Photographs and collage, Rachel Armstrong, August 2010. 
transform one landscape to become another. The process generally tends towards complexification, where simple cellular landscapes are replaced with multicellular ones. However, in conditions of scarcity, such as lightless caves that are inhabited by troglodytes with chemotrophic metabolisms (that derive their energy directly from chemistry, not the sun), succession may produce trends that reduce complexity. For example, troglodytes relinquish their eyes, as they are no longer necessary in their resource-constrained existence.

However, Venice is not a resource-constrained system. It is open to the sea and the light, and is bathed in the vigorous metabolic activity of its lagoon ecology. From a biological perspective, a city located in water, which is a universal solvent, may be regarded as a site for mineral release and, by virtue of the abundant waste that is emptied into the waterways, also as a rich source of organic compounds. These networks of vibrant matter are unevenly distributed by their context and form fertile landscapes of material transformation at many scales.

Venice has been imagined and constructed as a permanent structure within its continually shifting environment using traditional, inert building materials, such as marble, brick, iron, concrete, limestone and wood. Its entropy, therefore, is progressively increasing as a function of the physical laws of the universe, and is accelerated by natural processes that are digesting its fabric and redepositing it elsewhere. Although Venice has weathered the impact of its tempestuous environment for over three centuries, the lively non-human actants are imposing their own designs upon its materials and its integrity is crumbling. The visible deterioration of this iconic city has incited all kinds of impromptu acts of desperation to save the buildings from crumbling, where visitors and residents alike plug up the yawning, fist-sized holes in the wall with concrete, rubble, rubbish and even chewing gum (Artistic Things, 2009) $)^{63}$ (see Fig. 10.5).

The brickwork in Venice, at the shoreline and even above the level of the tide, is subject to an entanglement of forces exerted by heterogeneous groups of actants that continually work to reconfigure its chemical and physical relationships and leads to its structural decay (see Fig. 10.6).

In a biological sense, this is an act of transformation by the natural world, which is reclaiming the rarefied building materials back into a complex system of soils. Yet, Venice's vigorous resistance to these incessant environmental assaults is remarkably ingenious and lies at the heart of its development, as the city has survived by allying itself with advanced technologies of the time. In the 9th to 12th centuries, when the city-state of Venice was being founded, these technologies were agrarian. State of the art practices involved the drainage of land, the creation of canals and the use

63 Simone Decker's poignant commentary on chewing gum in Venice was created for the 1999 Venice Biennale, where she used photomontages of chewing gum to create the impression of life-sized installations and combined these with photographs of public spaces in the city. 


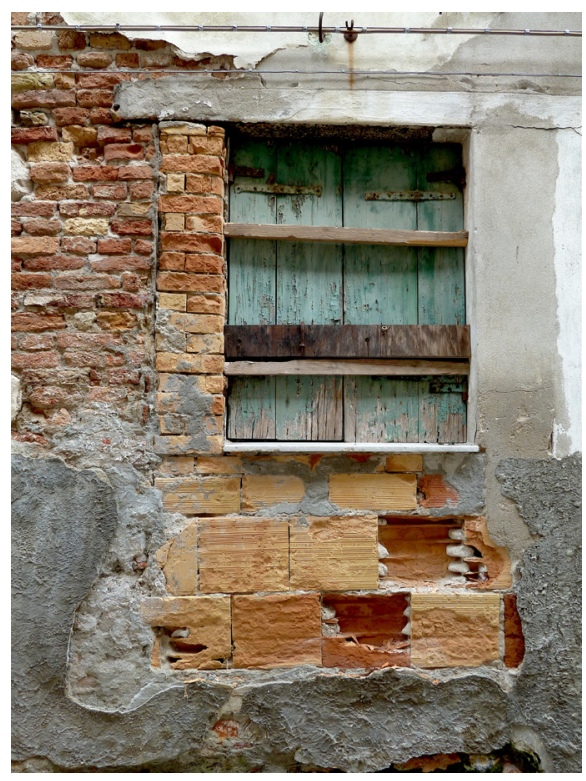

Figure 10.5: Gaps in Venetian brickwork appear to invite visitors to 'post' rubbish into the holes that the deterioration has left in the walls, such as this folded wedge of paper, which has been carefully

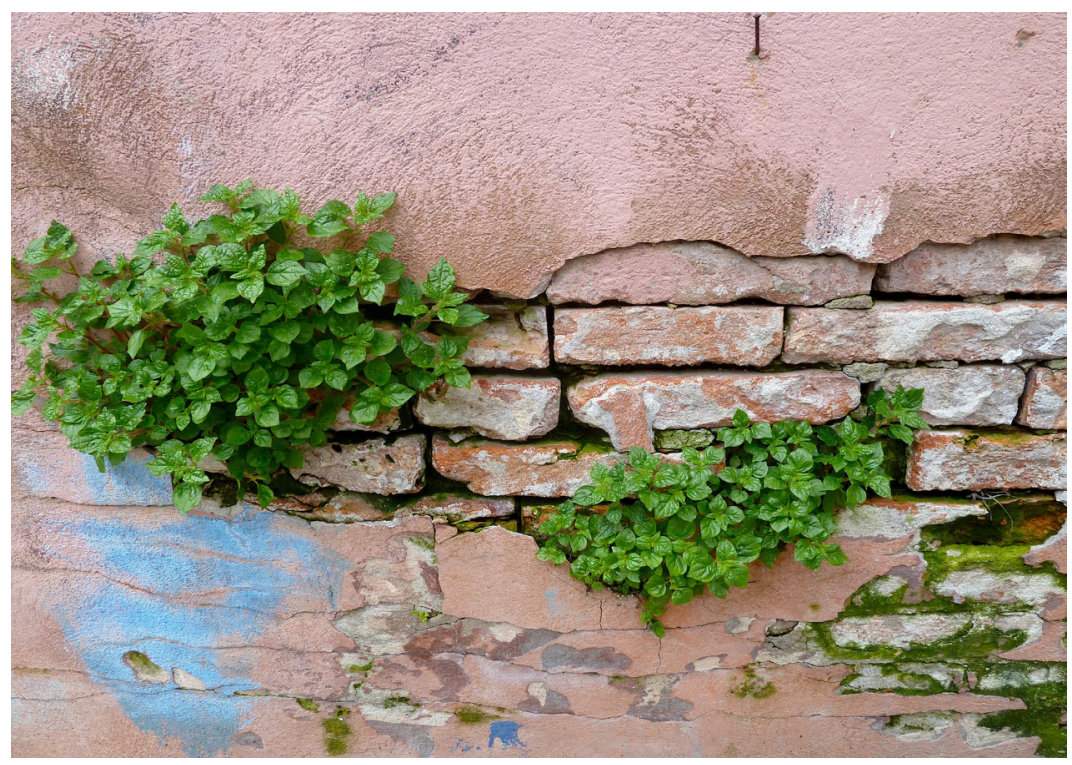

Figure 10.6: The structural decay of Venice's building fabric, coupled with the incorporation of organic matter into the new sites opened up by this process, is forged by the natural actants that cooperate through the production of assemblages that transform brickwork into new soils. Photograph, Rachel Armstrong, August 2010. 
of woodpiles under the foundations of the buildings to shore up the developing settlement (see Fig. 10.7).

These technologically enabled developments continue to form an essential part of the city today. With the Industrial Revolution, a new set of technologies exploded on to the scene, bringing great power and wealth to the people of Venice. This was implemented though the energy-intensive, top-down subordination of matter, which was executed with atomic-scale precision. Yet, with new technologies exploding on the scene, prompting rapid industrialization of the area, industrial machines quickly plundered Venice's rich resources (see Fig. 10.8).

Water consumption of Venice's aquifers caused the ground to sink beneath the city. This has contributed to the acqua alta, the high tides, which periodically flood the city and cause chemical and physical damage to the buildings. While industrialization vitalized the economy, it came at a great environmental cost, which Venice is still paying, in terms of pollution, a depleted water table and reduction in the rich lagoon biodiversity. However, the industrial age has also bestowed Venice with potential salvation - a colossal mechanical barrier that proposes to divide the city from its assailants. Construction of the MOSE (Modulo Sperimentale Elettromeccanico) project (Ravera, 2000) began in 2003 and is aimed for completion in 2014 (see Fig. 10.9).

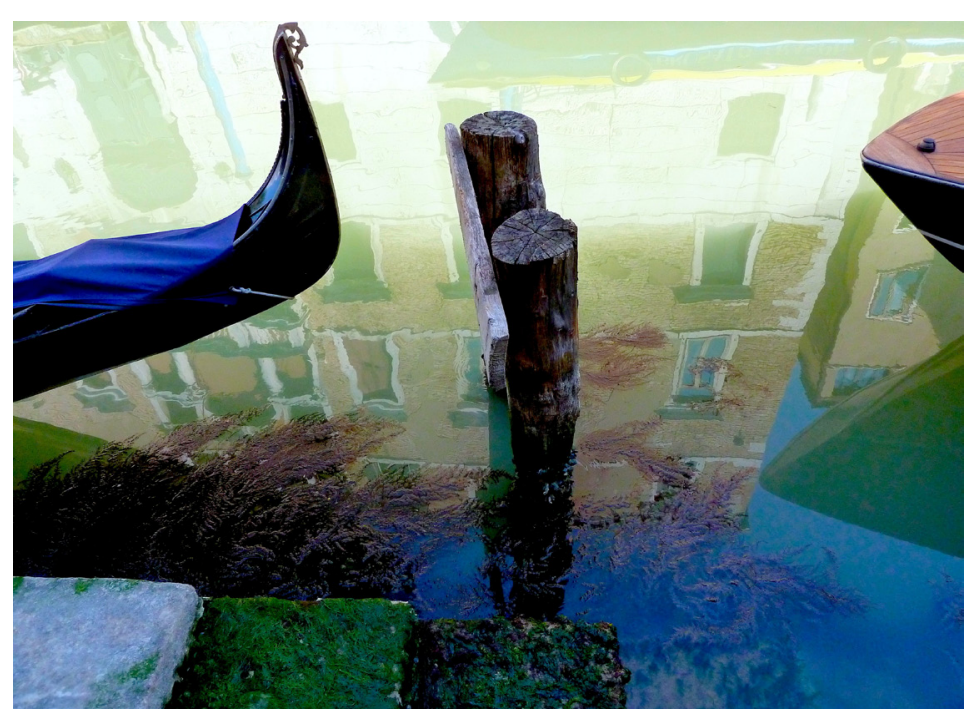

Figure 10.7: The visible wear and tear at this boat mooring's base mirrors the kinds of processes that shape Venice's foundations, which rest upon woodpiles. The salty marine water sank these into the soft delta soil, on which the city was established in mediaeval times, and they have generally been preserved. However, when woodpiles are exposed to the air, they are rapidly digested and transformed by marine organisms, such as bacteria and shellfish, and lose their structural integrity through decay. Photograph, Rachel Armstrong, August 2010. 


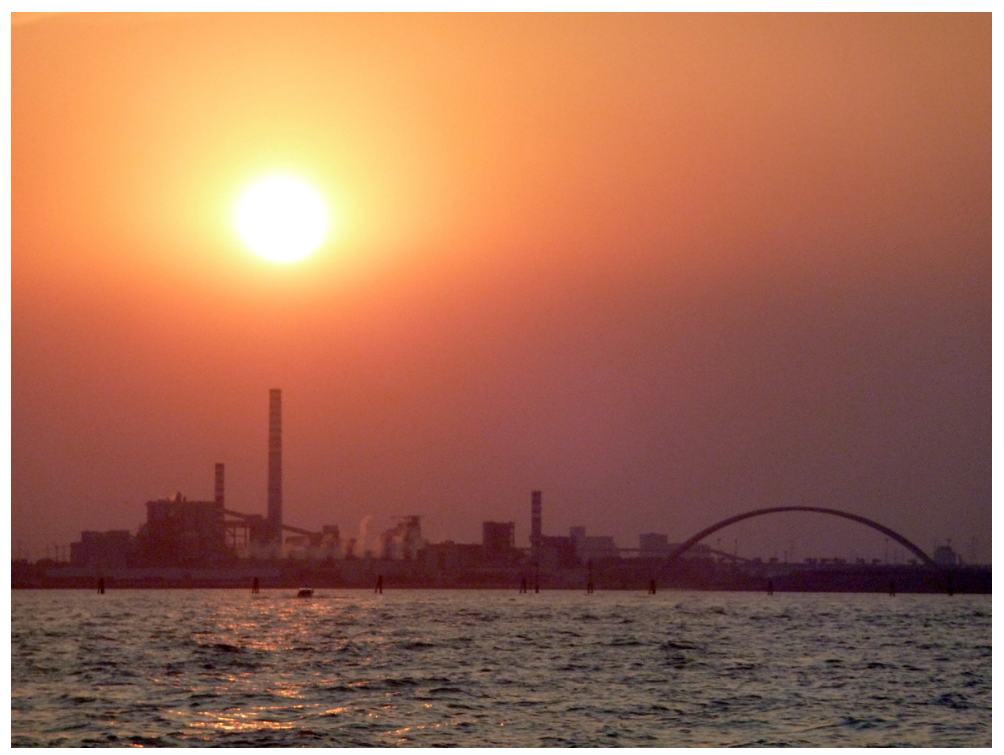

Figure 10.8: An oil refinery in Marghera, north of Venice, casts a shadow on the sunset of the historic city. Photograph, Rachel Armstrong, August 2010.

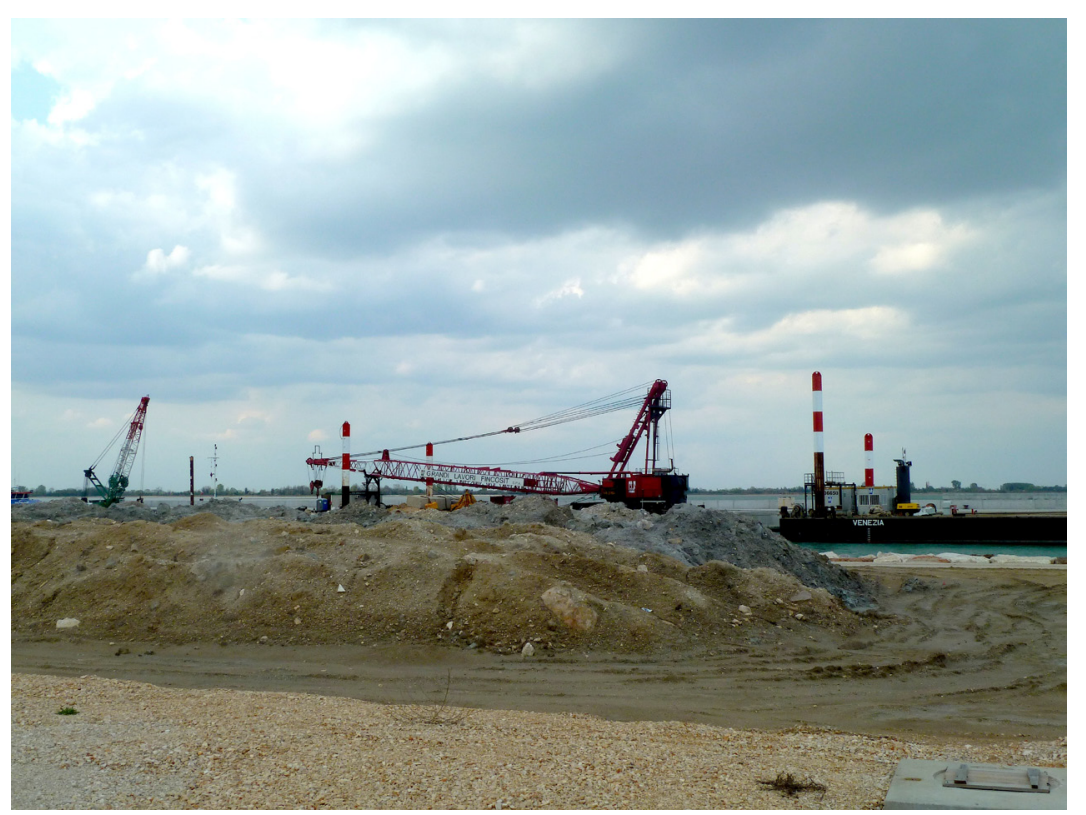

Figure 10.9: Construction site of the MOSE project from the Lido beach. Photograph, Rachel Armstrong, August 2010. 
It is a series of 78 hydraulically powered gates that propose to literally hold back the tide and ensure Venice's survival. Yet, ecologists are concerned about the backpressure of water on the natural drainage of the Po delta, which they fear may result in potentially devastating changes within the lagoon ecosystem (see Fig. 10.10).

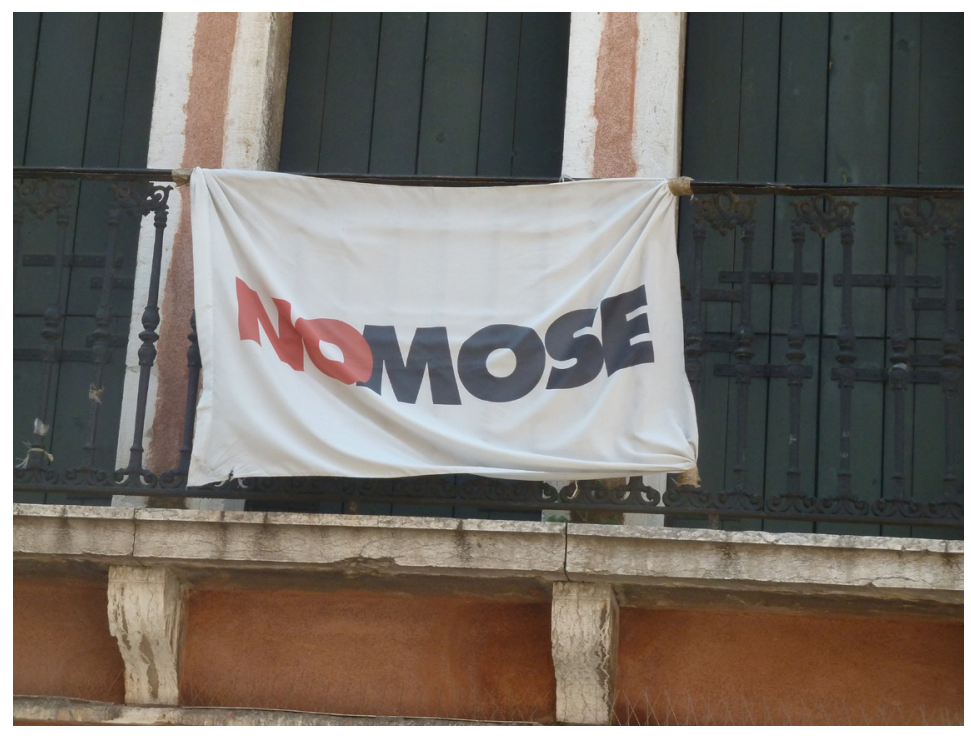

Figure 10.10: Banner protesting against the MOSE project. Photograph, Rachel Armstrong, August 2010.

\subsection{ELT as a Next Generation Technology in Venice's Survival Portfolio}

In keeping with Venice's progressive, technological engagement, the next generation of technologies designed to deal with Venice's uncertain predicament may incorporate the technologies of 'life' into its portfolio of tools. Living systems are much older than machines, and persist through networks and relationships that are continually forged through metabolic (interior) and ecological (exterior) assemblages (see Fig. 10.11). They exert 'soft power' rather than the 'hard power' of machines and work subtly with natural forces rather than standing in opposition to them (Nye, 1990). ${ }^{64}$

64 Joseph Nye first proposed the concept of 'soft power' to describe how persuasion and cooperation may exert influence on events, as opposed to 'hard power' that operates through domination and coercion to generate influence (Nye, 1990). 


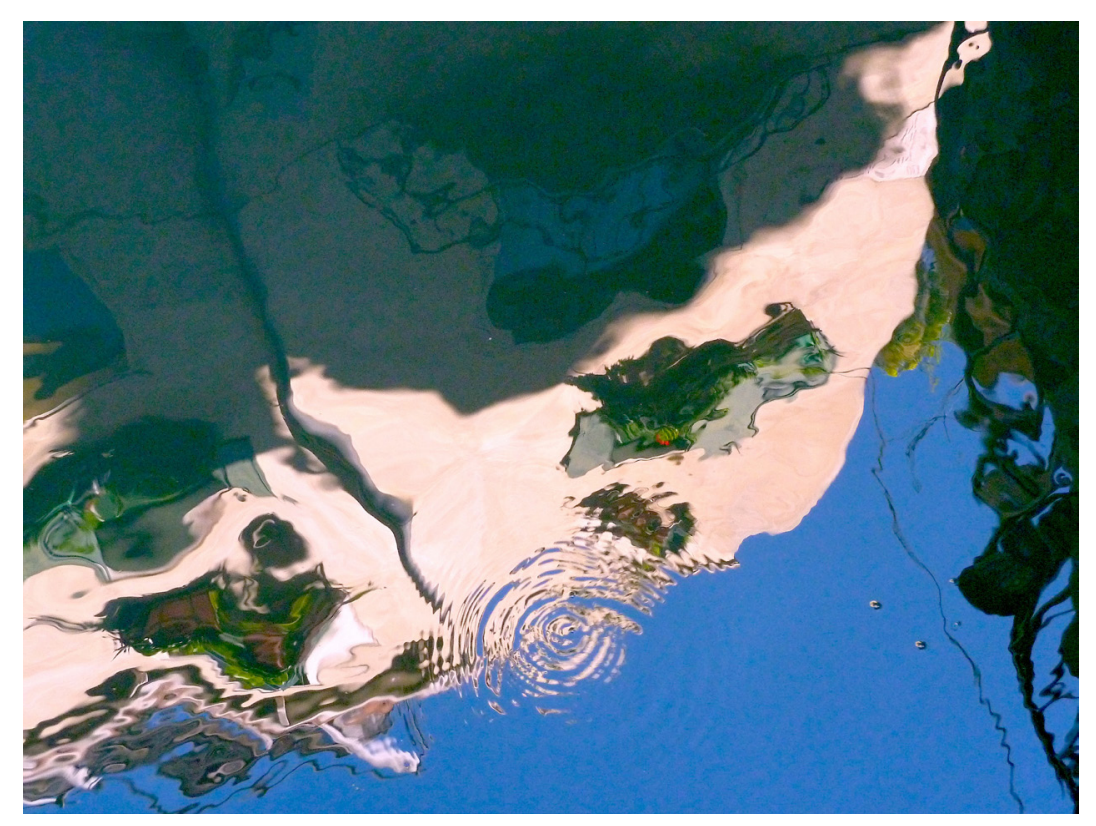

Figure 10.11: Multiple actants exert a variety of forces on the material assemblages that constitute Venice's fabric and include the relentless motion of water, wind, sunlight and the local marine ecology. Photograph, Rachel Armstrong, August 2010.

In the previous chapter, the Hylozoic Ground installation embodied an expression of next-generation technology, which harnessed some of the properties of living systems to generate environmentally contextualized outcomes. Various species of ELT within the cybernetic installation took the form of dynamic chemistries, which gave rise to a set of robust and flexible responses to the changing gallery conditions, by increasing the fertility ${ }^{65}$ of the site, recording events and producing microstructures in response to them. Despite the highly engaging experience embodied by Hylozoic Ground, much more research is needed to understand how architects can work with vibrant matter. Further investigations are also needed to establish how various species of lively materials may also benefit other disciplines that work and design with emergence, such as computing, ecology and urban planning practices. Technologies that can deal with probabilistic laws and events that may embrace the radical creativity (Kauffman, 2008, p.135) of Nature (Prigogine, 1997, p.5) are essential for establishing new methods of design practice. Tactics that forge new ecological relationships, which are not simply directed at creating a specific intervention, are needed, which may orchestrate architectural conditions through the production of assemblages. For example, vibrant matter may play a similar role to 'mother' trees, which possess such rich connections

65 Where 'fertility' refers to an increase in probability that a material event may occur. 
that they are critically important in nurturing the diverse ecosystems of our forests (Howard, 2011). The new linkages forged by ELT may confer otherwise inert fabrics with some of the qualities of living systems so they resist entropy and are also able to deal with environmental unpredictability in real time. The outcomes of these interventions are probabilistic, not deterministic, and require the kinds of managed engagement that are already familiar to agriculture, gardening or permaculture. However, these investments establish the conditions for the development of a qualitatively new kind of architectural design practice that regards the city of Venice not as a gated lagoon, but as an expanded ecosystem (Thackara, 2012).

Along the edges of the Venetian waterways is a native construction system that is not under human control. It is able to respond to the constant challenges of its hostile surroundings through constant growth, regeneration and repair. The actants of this construction system are, of course, Venice's marine biology, which use the technology of 'life' to persist in the face of perpetually changing environments. The local wildlife in Venice's waterways, such as algae, shellfish and bacteria, have claimed a construction process within this harsh terrain as their own (see Fig. 10.12).

They have evolved to accrete, secrete, remould and sculpt the materials of their surroundings to co-create microenvironments that are uniquely suited to their needs. While biology creates organisms with short lifespans in comparison to geological timescales, they are highly versatile and possess a range of strategies, which enables

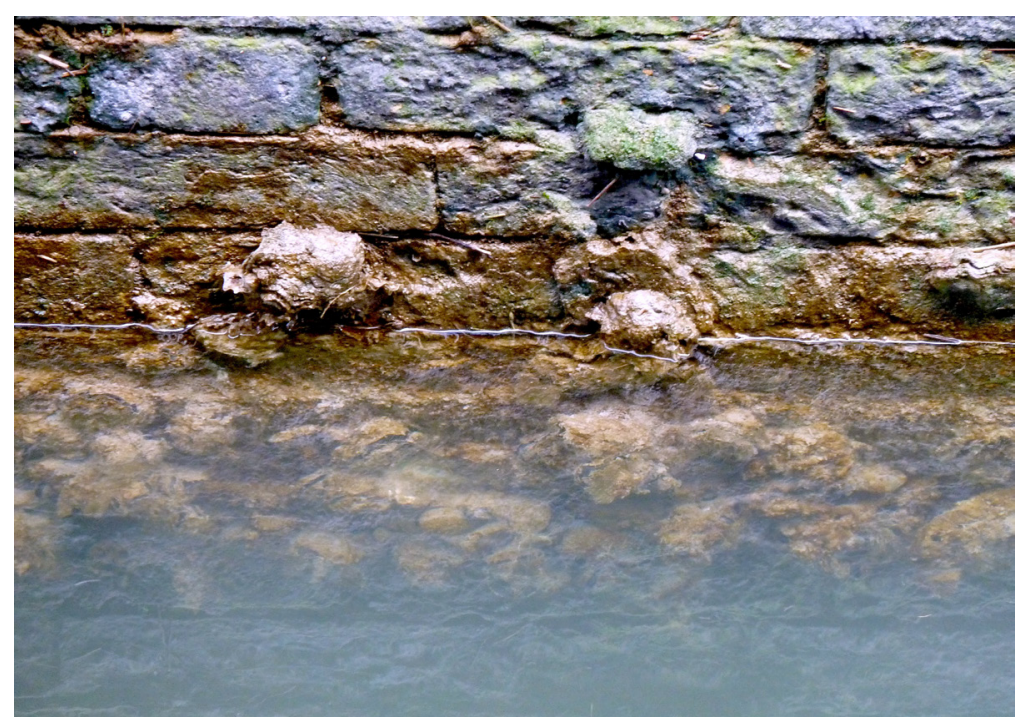

Figure 10.12: Tenuous marine wildlife secure attachment to Venetian brickwork and assimilate its materials to sustain their metabolism. In the process, these organisms transform the building fabric so that it is (re)appropriated into biological structures (as shells), or forms new soils (silt). Photograph, Rachel Armstrong, August 2010. 
them to creatively cope with the constant demands of an inconstant environment. Biology is resilient, adaptable and evolvable, and will survive unpredictable disturbances, which is in stark contrast to the local buildings that, no matter how durable, do not possess any of these qualities. Yet, currently Venice's native biology is undirected by human activity and threatens the integrity of its architecture, behaving like an unruly garden. Venetian wildlife exploit every opportunity to extend into new territories and environmental niches to claim them as their own, and they vigorously pursue easily accessible sources of nutrients from the fabric of the buildings.

The precarious situation of Venice embodies the condition of many modern cities, which are facing environmental disruption through the collective action of nonhuman forces, such as climate change and resource scarcity. An optimum approach to an environmental design may be to develop alternatives to the top-down, machinecentred approach of modern architecture, and replace or complement it with the bottom-up, self-organizing imperatives of actants. Natural systems already work by horizontally coupling the agency of dynamic systems at multiple scales and multiple levels of organization (subatomic, microscale, macroscale and megascale) through natural (Denning, 2007) and quantum computing approaches (Deutsch, 1997, p.123). Perhaps designers may be able to strategically influence the performance of urban assemblages by applying soft control systems using morphological computing techniques. By orchestrating the formation of strategic partnerships as a design intervention, the fabric of historic buildings could potentially be preserved, repaired or augmented - rather than destroyed.

This is more than a hypothetical proposition. Advances in biotechnology have provided us with a toolset that enables us to couple technology with Nature. The new science of 'synthetic biology' enables the design and engineering of living systems (Armstrong, 2013c) ${ }^{66}$ as it shares the common language of physics and chemistry with the natural world. Synthetic biology offers a set of tools, methods and materials that may provide a new, iterative relationship between manufactured and natural systems, which may be appropriated within architectural practice (Armstrong and Spiller, 2011).

Biology is vigorously synthetic and continually combines different kinds of chemical substrates to produce new compounds. In the same way that Venice has used advanced new technologies to assist its survival, so biology uses the naturally occurring technology of 'life' to persist in the face of perpetually changing environments. Local wildlife such as algae and shellfish actively accrete, secrete, remould and sculpt the materials of their surroundings to co-create microenvironments that are uniquely

66 Multiple definitions for synthetic biology exist ranging from genetic modification to molecular building blocks, which are described in detail in my analysis of the field for Volume magazine (Armstrong, 2013c). In this thesis, Stéphane Leduc's view of synthetic biology is applied, which is viewed as a branch of synthetic chemistry that exhibits lifelike properties. 
suited to their needs. This is in stark contrast to the fragility of local buildings that, like Ruskin's Matterhorn (Ruskin, 1989), will simply be worn down by Nature's relentless processes shaped by time's arrow (Prigogine, 1997, p.1) (see Fig. 10.13). However, currently Venice's native biology is undirected and the catabolic processes that also accompany its anabolic or synthetic activities do not discriminate between the minerals of a building and those in the marine environment. Without mediation, natural processes do not share our anthropocentric concerns, and threaten the integrity of Venice's historic architecture. They behave like an unruly garden, finding opportunities to extend into new territories and plunder new sites of abundance, to dismantle the high concentrations of easily accessible sources of nutrients from the fabric of the buildings.

\subsection{Chemically Programming the Fabric of Venice}

Although the most well-known forms of synthetic biology take a top-down approach to the design and engineering of living things by modifying the biological code of natural organisms, this is not the only means by which ELT obtains results. In recent years, dynamic droplet systems, which are programmable assemblages of chemistries that do not exist in Nature, can be used as alternative production platforms to machines (Hanczyc et al, 2007; Toyota et al, 2009). They work by

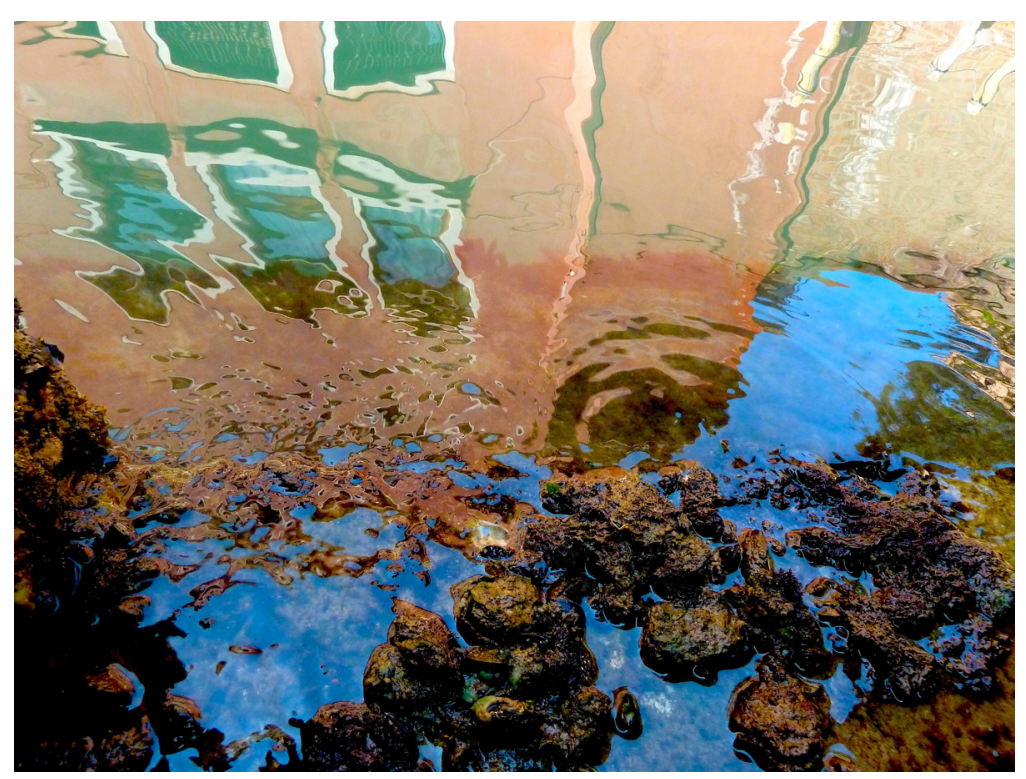

Figure 10.13: Light falling on a mooring step in Venice that houses a colony of microalgae, which have produced thrombolites. Photograph, Rachel Armstrong, August 2010. 
facilitating horizontal material couplings between agents, which may be orchestrated through morphological computing techniques. Since these actants are not biological, they are easily programmable, and altering their internal and external chemical programs may shape their actions. For example, droplets could be constructed that are sensitive to light and move away from it. They may also be designed to produce a mineral shell using dissolved substances when they are at rest. These processes are likely to be context sensitive and therefore will vary depending on the composition of the local environment. Since Venice rests upon woodpiles, its foundations offer an environment in which a variety of ELT species could be designed to produce a material - potentially at an architectural scale - by harnessing the en masse effects of chemically programmed dynamic droplets. Morphological computing techniques could be used to orchestrate the production of an artificial limestone-like reef by chemically manipulating the activity of droplets (see Fig. 10.14).

Indeed, a range of species of ELT could be designed and released directly into the waterways, and chemical attractants could be used to ensure infiltration of the technology where conditions for penetration are poor. It is possible that dynamic droplet species may even be able to move with such force that they resist currents and chemical gradients. For example, a species of droplet could be designed with combined qualities so it could move away from the light-filled waterways and then construct artificial mineral shells at rest under the darkened foundations of the city, as in Figs. 10.15 and 10.16. However, unlike tipping concrete into the water, the chemically programmable droplets would be sensitive to the biotic environment.

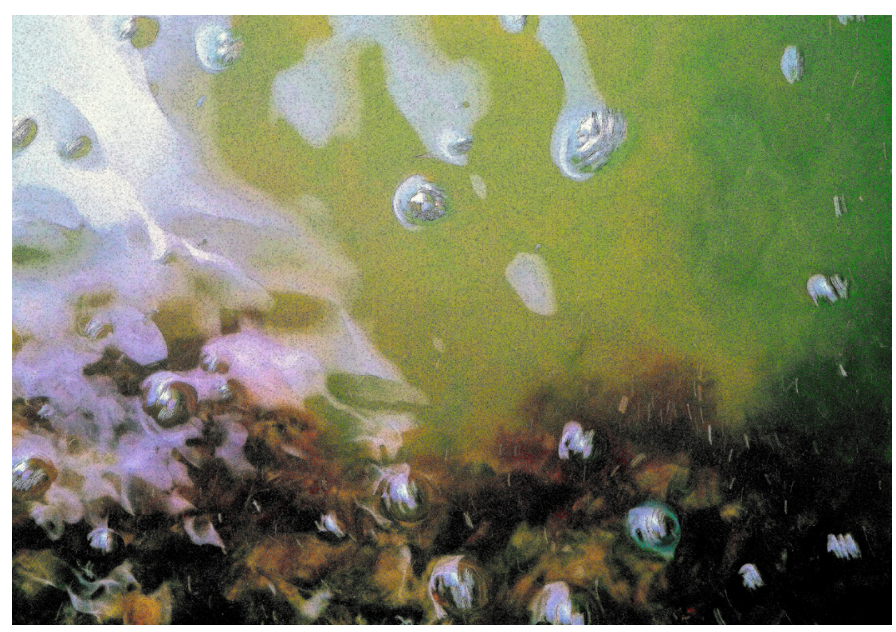

Figure 10.14: Dynamic droplets programmed to move away from the light and down into the darkened foundations of the city could potentially be designed as a city-scale morphological computer to construct an artificial limestone reef underneath Venice's foundations. Photograph, Rachel Armstrong, August 2010. 
The chemical composition, texture and colour of the accreted material are likely to change with time as minerals and conditions in the water vary. The first manifestations of the active technology are based on an oily hardware and therefore produce soft, spongy materials that settle around the woodpile foundations. While many will be crushed by water turbulence, they can robustly resist being destroyed by the vigorous tides, and even recover after being nibbled by marine life. Gradually, more rigid structures with delicate, thin shells may replace the soft structures,

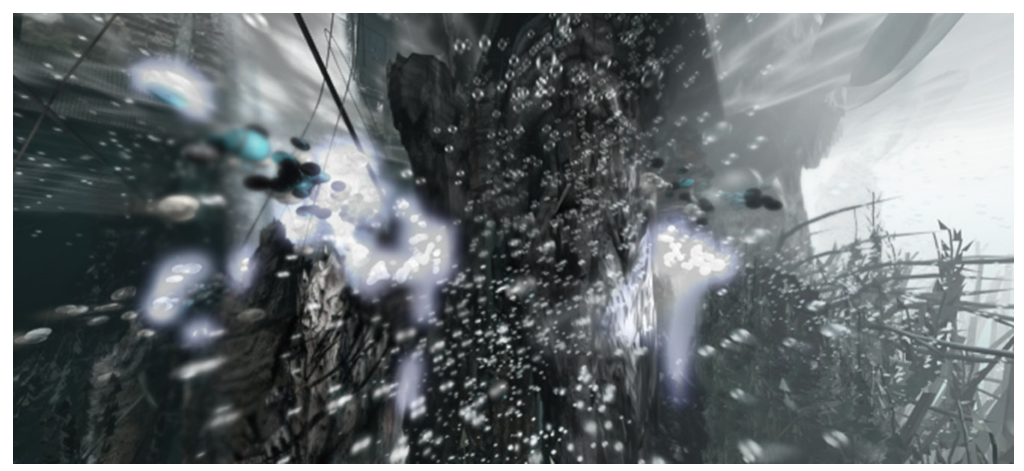

Figure 10.15: View underneath Venice's foundations, which stand upon woodpiles, demonstrating the potential action of a city-scale morphological computer composed of smart, programmable droplets. This structure aims to gradually spread the point load of the city over a much broader base than offered by the narrow woodpiles, as well as providing new ecological niches for the marine wildlife. Computer drawing, Christian Kerrigan, February 2009.

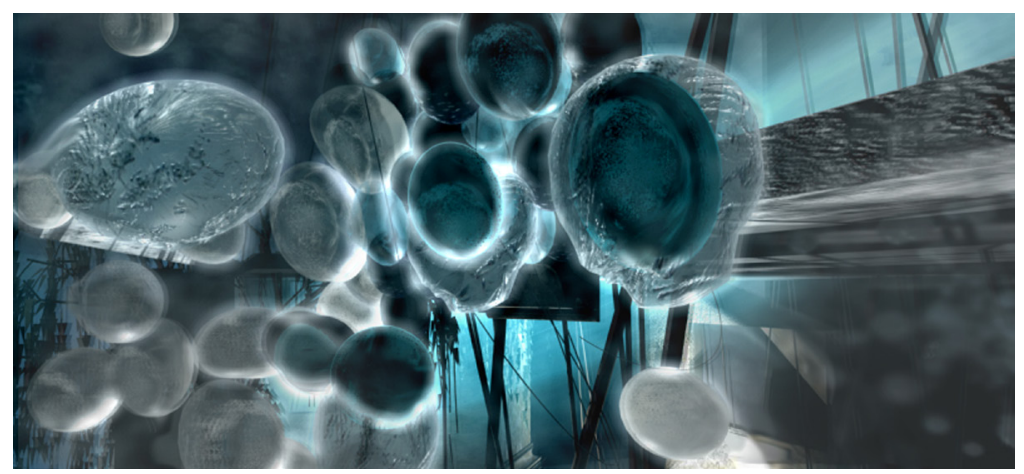

Figure 10.16: View of programmable droplets coming to rest underneath Venice's foundations as their light-sensitive metabolism reaches equilibrium and activates a second metabolic process that enables the droplets to use local minerals and dissolved carbon dioxide to grow a solid, reef-like structure. Computer drawing, Christian Kerrigan, February 2009. 
and some will persist to create porous, pumice-like assemblages. The resulting construction would offer a supporting framework for the city and marine wildlife, as well as serving as a pollution sequestration system which was capable of growth and repair.

Mineralization of 'bimorph' crystals ${ }^{67}$ could be promoted by releasing a new species of silica-containing droplet into the Venice waterways, which may technologically strengthen the mineralization process (under alkaline conditions) (Kellermeier, 2012). Wim Noorduin demonstrated that controlling the environmental chemical conditions of bimorph crystals could accurately produce flower-like microstructures. The exact morphology of the crystals depends on how the different substances diffuse through a liquid silica-based solution and is sensitive to the presence of certain chemical gradients, as the acidity of the reaction changes spontaneously during the crystallization process. The reaction conditions determine whether the structure resembles broad leaves, thin stems or petal rosettes (Harvard School of Engineering and Applied Sciences, 2013).

Gradually, the shells produced by droplets would be shaped by the chemistry within micro niches around hollows in the woodpiles. Further synthetic mineralizing activity would then be sculpted by new generations of smart droplets. Additionally, local marine life such as shellfish are also likely to be drawn by the abundance of mineral resources in the site. Although this scheme has not yet been formally tested in the laboratory, it is very likely that the smart droplets, simply put, provide a more attractive food source for these organisms. Their minerals would be much more accessible to the marine wildlife than the existing sources in the brickwork of the Venetian buildings. Should that be the case, something remarkable would happen. In the presence of smart droplets, the same organisms that have previously 'preyed' on the brickwork and the wooden poles will do the exact opposite. They may produce resilient calcium-rich materials that are chemically adhered to the brickwork, which stops the further action of physical and chemical forces eroding the man-made materials. Moreover, new populations may be chemically attracted to the area in which the smart droplets are making high levels of minerals available by simply concentrating them in thin shells. So, as one population of droplets creates a layer of mineral shells, another takes root on its surface, and gradually a material is accreted that grows from the inside outwards. The deceased members of the colony give up their 'bones' to form a collective 'skeleton' or 'scaffolding' for a community, which forms a sturdy platform for the next generation, which is exactly how a reef forms.

67 The term 'biomorphic' crystal applies to inorganic matter that adopts biological-like forms. These may be synthesized from a highly alkaline ( $\mathrm{pH}$ 9-11) silicate solution using salts from Group 2A in the periodic table, which includes magnesium, calcium, barium, strontium and radium and produce shapes commonly assumed to be characteristic of life such as, helices and convoluted curved sheets (Carnerup et al, 2006, p.248). 
So, the droplets produce a reef directly and indirectly by creating the conditions for marine biology to co-produce the reef alongside them. With time, it is even possible that new species of shell-producing wildlife may evolve, which will be able to resolve sunlight abundance with the ability to make strong shells. Gradually, the accretion process may produce an artificial limestone reef underneath the foundations of the city. Ultimately, the proliferation of the reef under the city could provide a counterforce that is strong enough to stop Venice from sinking into the soft delta soils on which it was founded (see Fig. 10.17).

\subsection{Experiments on Programmable Droplets}

A number of experiments to demonstrate the feasibility of this proposal have been conducted both in the laboratory and in the field although the degree of penetration

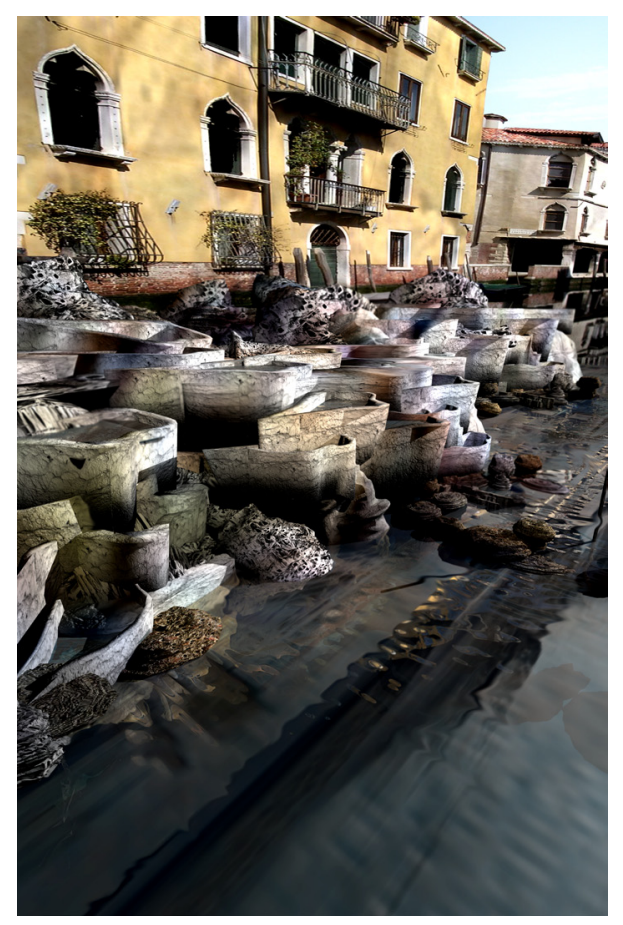

Figure 10.17: Droplet assemblages may produce porous, pumice-like formations over time that reflect mineral compositions through their coloured layers, like stromatolites (Shark Bay World Heritage Area, 2009). The resultant architecture does not obey a top-down paradigm, but is codesigned through the entangled metabolic interactions between marine and human populations. Computer drawing, Christian Kerrigan, February 2009. 
of the city foundations by the smart droplets has not been tested, nor has the ideal position from which to release the technology been established. ${ }^{68}$

\subsubsection{Droplet Design}

'Protopearls' were developed with chemist Hans Toftlund and Martin Hanczyc as a demonstration model system to explore the possibility of a technology that could strategically distribute minerals spatially and temporally and in response to environmental cues.

The first series of experiments were conducted courtesy of Davide De Lucrezia at Biotech Explora in Marghera Science Park, Italy, and with Martin Hanczyc at the Center for Fundamental Living Technology (FLinT) at the University of Southern Denmark. The technological design principles and conditions for producing a mineral shell around an oil droplet using lagoon water were explored. An oil droplet in water system was selected as the vehicle for a mineralizing metabolism. The clear oil diethyl phenyl phthalate (DEPP) was used as the oil carrier, which is the same oil that was used to house the Carbon Eater metabolism for the Hylozoic Ground installation. Although DEPP in aqueous phase is not vigorous or lifelike in the way that other oil/ water systems may be (Hanczyc et al, 2007; Toyota et al, 2009), its specific gravity $\left(1.1\right.$ at $\left.20^{\circ} \mathrm{C}\right)$ is heavier than water and was thought to be a more suitable carrier for ingredients to facilitate accretion around woodpiles than a lighter oil, whose activity would be directed at the water's surface.

Since DEPP's specific gravity is temperature sensitive, it could work at different levels in the water. Below $25^{\circ} \mathrm{C}$, the oil droplets sink, and at higher temperatures they rise to the surface and spread out. The metabolism selected for distribution by the droplets was designed to reflect the natural salts present in the lagoon, which is rich in magnesium and calcium. These salts are formed by alkaline earth metals from Group 2A of the periodic table, which includes magnesium, calcium, barium, beryllium, radium and strontium. Significant work by Juan García-Ruiz on the precipitates of 'basic' salts formed by barium and strontium showed that unusual crystal growth mechanisms in alkaline silica-rich environments could produce 'witherite' (a barium carbonate mineral in the aragonite group) precipitates from barium chloride and silica solutions (García-Ruiz, Melero-García and Hyde, 2009). These deposits were referred to as 'silica/carbonate bimorphs' because of their striking resemblance to primitive organisms. The aggregates of self-assembled materials were solely of inorganic origins and were composed of an amorphous phase of silica, which was intimately intertwined with a carbonate nanocrystalline phase. García-Ruiz and colleagues

68 Detailed tests, analyses, surveys and models will need to be made before this project is realized, which is beyond the scope of this current research. 
proposed that the mechanism for producing such striking lifelike formations could be explained by coupled co-precipitation of carbonate and silica, which induced fibrillation of the growing front and gave rise to laminar structures that curled at their growing edges (García-Ruiz, Melero-García and Hyde, 2009).

Based on García-Ruiz and colleagues' observations, a demonstration experiment was designed with chemist Hans Toftlund at the University of Southern Denmark to form artificial shell-like structures from biomorphic crystals at the oil/water interface of DEPP droplets, which were loaded with a metabolic substrate comprised of soluble barium or calcium chloride salts. Barium salts were the control system for the experiment, having already been identified by García-Ruiz and colleagues as producing biomorphic crystal growth (García-Ruiz, Melero-García and Hyde, 2009), while calcium salts were the desired substrate for mineralization of the proposed artificial reef. Yet the properties of calcium had not been explored in the 2009 Science paper, so a preparation was designed to expose them to the same alkaline/silicate conditions as the barium salts. Both species of droplets (barium and calcium) were prepared by mechanically grinding 0.001 moles of salt per $2 \mathrm{ml}$ of DEPP to form a paste. Each petri dish was prepared by adding $15 \mathrm{ml}$ of water, which had been alkalinized by adding $0.2 \mathrm{ml}$ of sodium hydroxide to reach a $\mathrm{pH}$ of between 8.5 and 10 (García-Ruiz, Melero-García and Hyde, 2009). ${ }^{69} 0.6 \mathrm{ml}$ of waterglass (sodium silicate solution) was added to this solution and gently stirred until fully dissolved using a plastic spatula. The petri dish was left open to the air so that atmospheric carbon dioxide could dissolve and form carbonate and bicarbonate species. Finally, two to six droplets of separate species of metabolic DEPP were added to the petri dish for both calcium and barium preparations. They were left to stand at room temperature ${ }^{70}$ to form crystalline precipitates for 12-36 hours. The ingredients for both protopearl preparations are summarized in Table 10.1 and Table 10.2.

The droplet interfaces of both barium and calcium preparations were rapidly mineralized in solution in the presence of alkaline sodium silicate at $\mathrm{pH}>8.5$. The dense white precipitates around the spherical oil droplets appeared pearl-like and were colloquially referred to as 'protopearls'.

\subsubsection{Barium Protopearls}

Rapid mineralization occurred at the droplet interface of the DEPP droplets carrying barium chloride, and within a few hours a fluffy, vigorous white precipitate had formed at their surface (see Fig. 10.18).

69 García-Ruiz and colleagues recommend alkaline conditions with a pH range between 8.5 and 11 (García-Ruiz, Melero-García and Hyde, 2009).

70 Room temperature being $20^{\circ} \mathrm{C}$. 
Table 10.1: Barium carbonate protopearls preparation

\begin{tabular}{lll}
\hline Substance & Strength & Amount \\
\hline DEPP & $\mathrm{n} / \mathrm{a}$ & $2 \mathrm{ml}$ per droplet \\
$\begin{array}{l}\text { Sodium silicate solution } \\
\text { (waterglass) }\end{array}$ & $\begin{array}{l}\text { Sigma Aldrich, } \geq 10 \% \mathrm{NaOH} \text { basis, } \\
\geq 27 \% \mathrm{SiO}_{2} \text { basis }\end{array}$ & $2 \mathrm{ml}$ per $50 \mathrm{ml}$ water \\
Sodium hydroxide & $1 \mathrm{M}$ & $0.2 \mathrm{ml}$ per $15 \mathrm{ml}$ water \\
Barium chloride & $0.2 \mathrm{~g}(0.001 \mathrm{~mol})$ & $\begin{array}{l}\text { Mechanically ground into each } 2 \mathrm{ml} \\
\text { aliquot of DEPP to form paste }\end{array}$ \\
\hline
\end{tabular}

Table 10.2: Calcium carbonate protopearls preparation

\begin{tabular}{lll}
\hline Substance & Strength & Amount \\
\hline DEPP & $\mathrm{n} / \mathrm{a}$ & $2 \mathrm{ml}$ per droplet \\
$\begin{array}{l}\text { Sodium silicate solution } \\
\text { (waterglass) }\end{array}$ & $\begin{array}{l}\text { Sigma Aldrich, } \geq 10 \% \mathrm{NaOH} \text { basis, } \\
\geq 27 \% \mathrm{SiO}_{2} \text { basis }\end{array}$ & $2 \mathrm{ml}$ per $50 \mathrm{ml}$ water \\
Sodium hydroxide & $1 \mathrm{M}$ & $0.2 \mathrm{ml}$ per $15 \mathrm{ml}$ water \\
Calcium chloride & $0.1 \mathrm{~g}(0.001 \mathrm{~mol})$ & $\begin{array}{l}\text { Mechanically ground into each } \\
2 \mathrm{ml} \text { aliquot of DEPP to form paste }\end{array}$ \\
\hline
\end{tabular}

After around three hours, precipitation in the petri dishes became diffuse and was not limited to the surface of the DEPP droplets. This was due to the barium salt diffusing from the body of the DEPP droplet and equilibrating within the petri dish, which occurred after six hours. Examination using a Nikon Eclipse TE2000-S inverted microscope with a Photometrics Cascade II 512 camera and in-house software revealed 'wheatsheaf' shaped crystals characteristic of barium carbonate at a magnification of $10 \times$.

\subsubsection{Calcium Protopearls}

The calcium chloride carrying DEPP droplets rapidly mineralized at the oil/water interface, where a fine white precipitate formed (see Fig. 10.19). After 24 hours, precipitation within the petri dish was observed as the calcium equilibrated within the petri dish. After 48 hours, the stabilized droplets were observed under a light microscope at 10× magnification using a Nikon Eclipse TE2000-S inverted microscope with a Photometrics Cascade II 512 camera and in-house software, where 'tetrahedral' shaped crystals, characteristic of calcium carbonate, were observed, assembled in brittle, shell-like formations. 

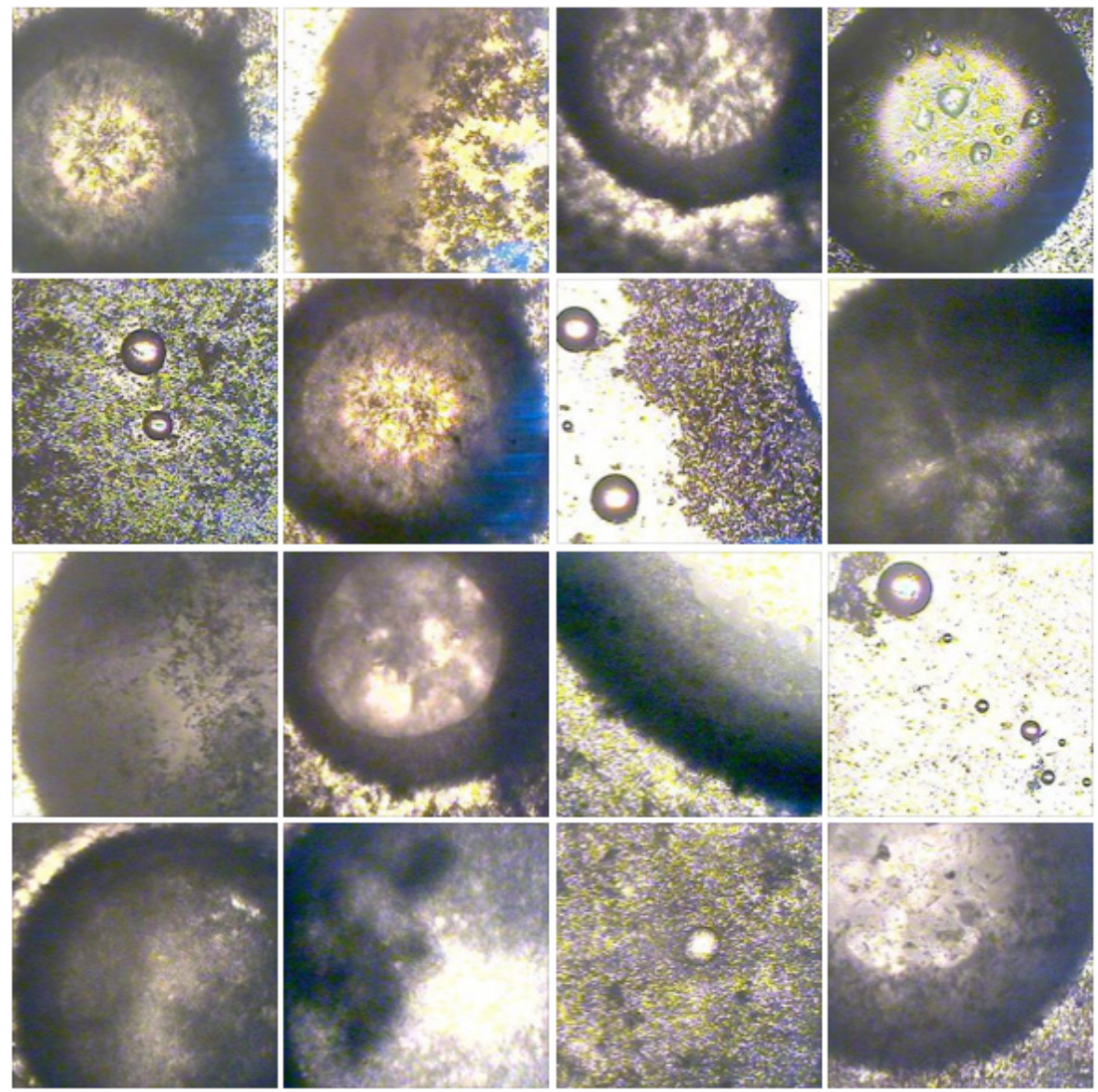

Figure 10.18: Barium protopearls are produced when an oil droplet is used as a slow-release carrier system for a simple carbon-fixing metabolism, which produces insoluble carbonate at the oil/water interface in the presence of dissolved carbon dioxide. The droplets quickly become coated with a feathery precipitate (classically described as a 'wheatsheaf'), which forms a simple mineral shell around the oil droplets, giving it a 'pearl-like' appearance. Micrographs and collage, magnification 4×, Rachel Armstrong, February 2009.

\subsubsection{Protopearl Interactions with Other Materials}

The DEPP protopearl droplets of both barium and calcium species robustly settled under gravity and produced soft scaffolding that could withstand vigorous agitation, re-forming droplets as soon as the physical activity ceased. Their ability to form assemblages and associations with other materials was demonstrated in a series of exploratory experiments where the droplets were added to containers with architectural substrates, including brick, wood, concrete and steel, that were submerged in alkaline solutions of $\mathrm{pH}>8.5$. 

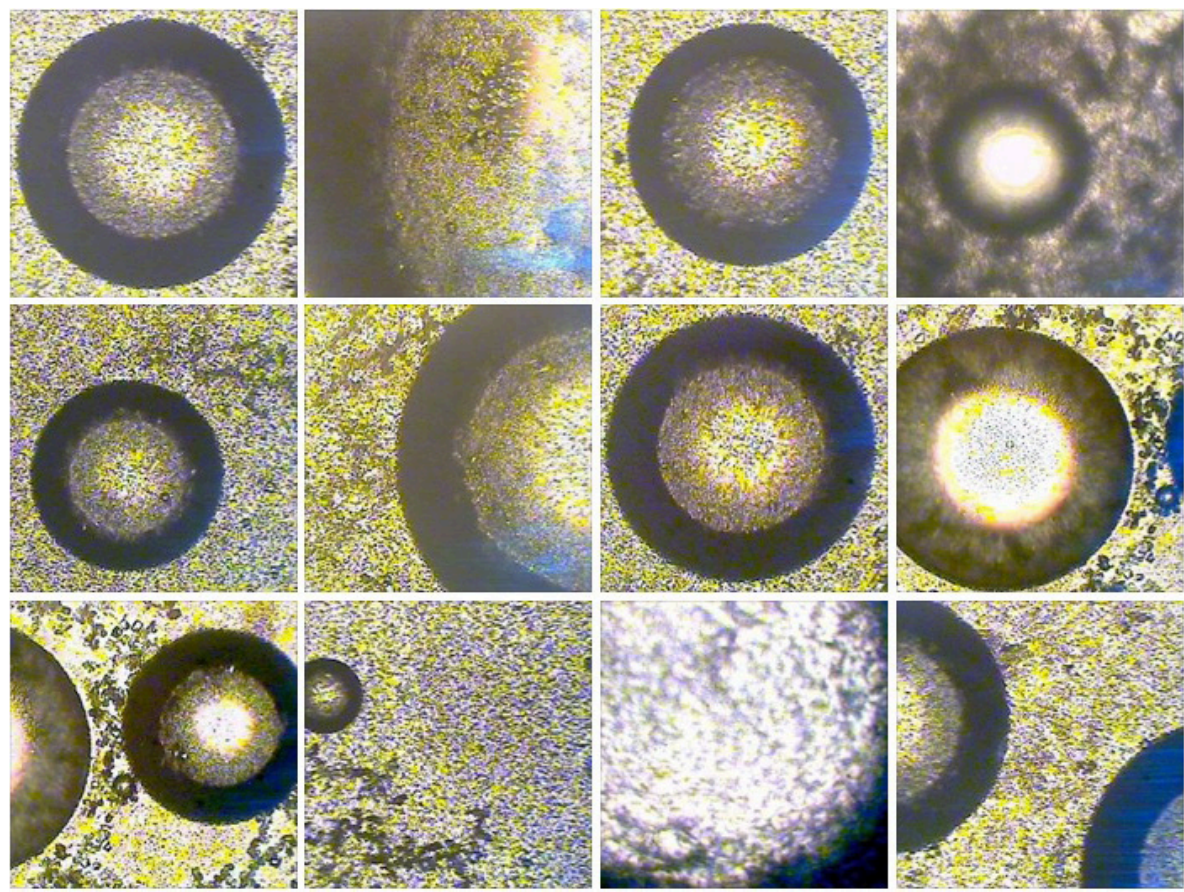

Figure 10.19: Calcium protopearls are produced when oil droplets that slowly release a soluble calcium salt as a simple carbon-fixing metabolism produce insoluble carbonate at the oil/water interface in the presence of dissolved carbon dioxide. The droplets quickly become coated with a dense, crystalline precipitate, which forms a bright white, simple mineral shell around the oil droplets that bestows them with a dramatic 'pearl-like' appearance. Micrographs and collage, magnification 4×, Rachel Armstrong, February 2009.

\subsubsection{Brick}

A variety of brick fragments were gathered from rubble in the streets of Venice and brought to the Biotech Explora laboratory, where they were added to a large $50 \mathrm{ml}$ petri dish (see Fig. 10.20). The brick fragments were submerged in $40 \mathrm{ml}$ tap water and titrated to $\mathrm{pH} 8.5$ using sodium hydroxide at room temperature. DEPP paste containing calcium chloride was made up to $10 \mathrm{ml}$ and aliquots of $1 \mathrm{ml}$ were added to the water (in the absence of sodium silicate). The clear DEPP droplets turned white with calcium carbonate surface precipitation within 5-10 seconds after being added to the water and settled under gravity. Some of the droplets were mechanically divided by the brick fragments and formed smaller droplets. The droplets were not observed over a period of two hours, where no further movement or division of the oil bodies was observed, nor did any precipitate or residue form. The reason for this is unknown but may be due to silicates present in the brickwork and also due to the practical time constraints on the experiment. Further characterization and exploration of the interactions between the biomorphic crystals and the brickwork at the microscopic level requires further study. 

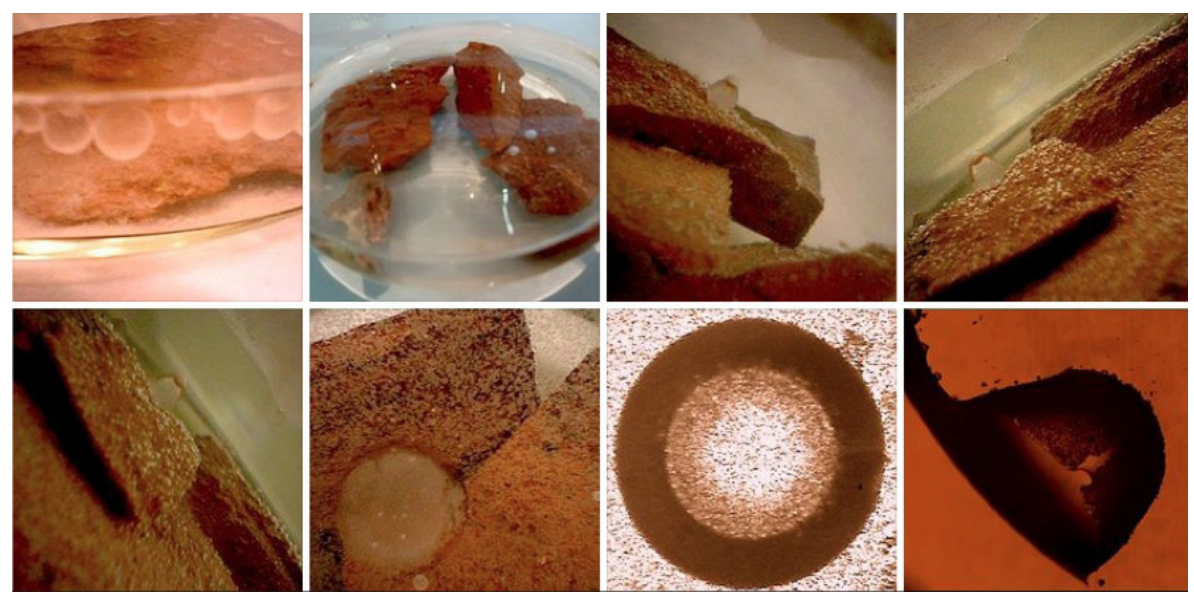

Figure 10.20: In the presence of brick fragments, when DEPP - with a simple carbon-fixing metabolism - was introduced into a container with Venetian lagoon water, rapid mineralization of the oil/water interface occurred vigorously producing 'protopearls'. Photographs and collage, magnification 4×, Rachel Armstrong, February 2009.

\subsubsection{Wood}

Untreated wood fragments were gathered from the university campus at the University of Southern Denmark and taken to the FLinT laboratory where they were added to a large $500 \mathrm{ml}$ glass beaker (see Fig. 10.21). The wood fragments were submerged in $400 \mathrm{ml}$ tap water and titrated to $\mathrm{pH} 8.5$ using sodium hydroxide at room temperature. DEPP paste containing calcium chloride was made up to $10 \mathrm{ml}$ and aliquots of $1 \mathrm{ml}$ were added to the water (in the absence of sodium silicate). The clear DEPP droplets turned white with calcium carbonate surface precipitation within 5-10 seconds after being added to the water where they rapidly descended and settled under gravity. After 48 hours, the droplets had developed a brittle calcium carbonate shell and a small amount of precipitate formed around the droplets.

\subsubsection{Concrete}

Concrete shards were gathered from the university campus at the University of Southern Denmark and taken to the FLinT laboratory where they were added to a large $500 \mathrm{ml}$ glass beaker (see Fig. 10.22). The splinters of concrete were submerged in $400 \mathrm{ml}$ tap water and titrated to $\mathrm{pH} 8.5$ with sodium hydroxide at room temperature. DEPP paste containing calcium chloride was made up to $10 \mathrm{ml}$ and aliquots of $1 \mathrm{ml}$ were added to the water (in the absence of sodium silicate). The clear DEPP droplets turned white with calcium carbonate surface precipitation within 5-10 seconds after being added to the water where they rapidly descended and settled under gravity. After 48 hours, the droplets had developed a brittle calcium carbonate shell and a small amount of precipitate had also formed around the droplets. 


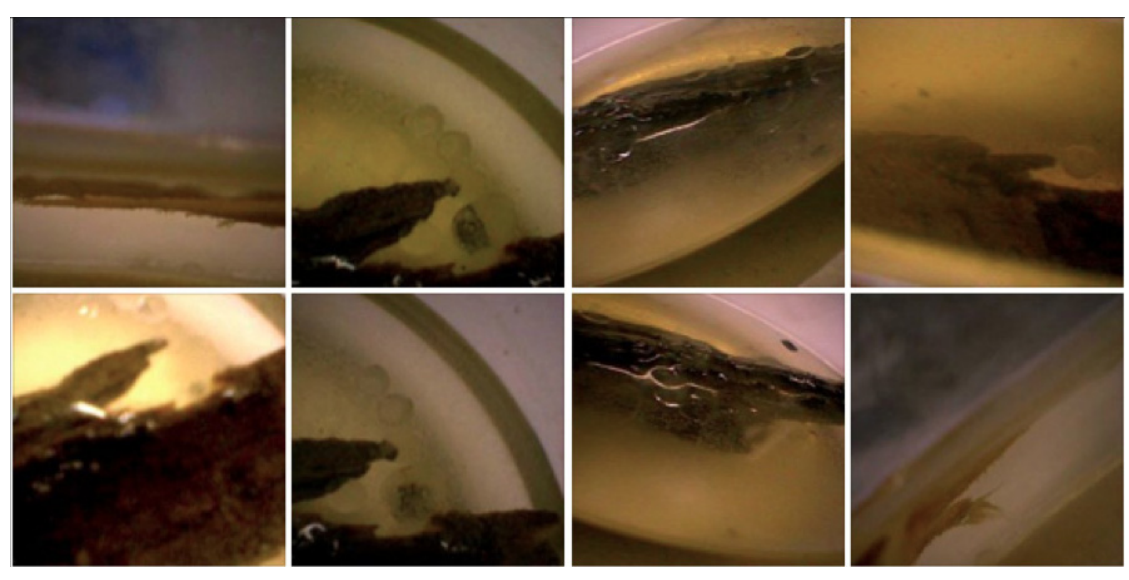

Figure 10.21: In the presence of wood fragments, malleable DEPP droplets with a 'protopearl' metabolism tended to roll off the wood and settle on the bottom of the container. Photographs and collage, Rachel Armstrong, February 2009.

\subsubsection{Steel}

A rusty six-inch bolt and stainless steel nail were sourced from a rubbish skip at the maintenance workshop at the University of Southern Denmark (see Fig. 10.23). They were taken to the FLinT laboratory where they were each added to a large $500 \mathrm{ml}$ glass beaker. The nail and bolt were separately submerged in different containers of $400 \mathrm{ml}$ tap water and titrated to $\mathrm{pH} 8.5$ with sodium hydroxide at room temperature. DEPP paste containing calcium chloride was made up to $10 \mathrm{ml}$ and aliquots of $1 \mathrm{ml}$ were added to the water in each container (in the absence of sodium silicate). In both containers, clear DEPP droplets turned white with calcium carbonate surface precipitation within 5-10 seconds after being added to the water, where they rapidly descended and settled under gravity. After 48 hours, the droplets had developed a brittle calcium carbonate shell but had not made any bond with either the bolt or the nail. A small amount of precipitate had formed around the droplets in the beaker with the new nail and a more diffuse, dirty brown precipitate had formed at the bottom of the beaker with the rusty bolt.

\subsubsection{Observations}

The protopearls provided a model system to interrogate the possibilities of designing a light-activated, carbon-fixing droplet technology that could potentially accrete dissolved chemicals over its surface to produce a solid structure. In principle, it was demonstrated that dynamic droplets could be programmed to produce limestone-like deposits, which interacted with common building materials and were most vigorous 

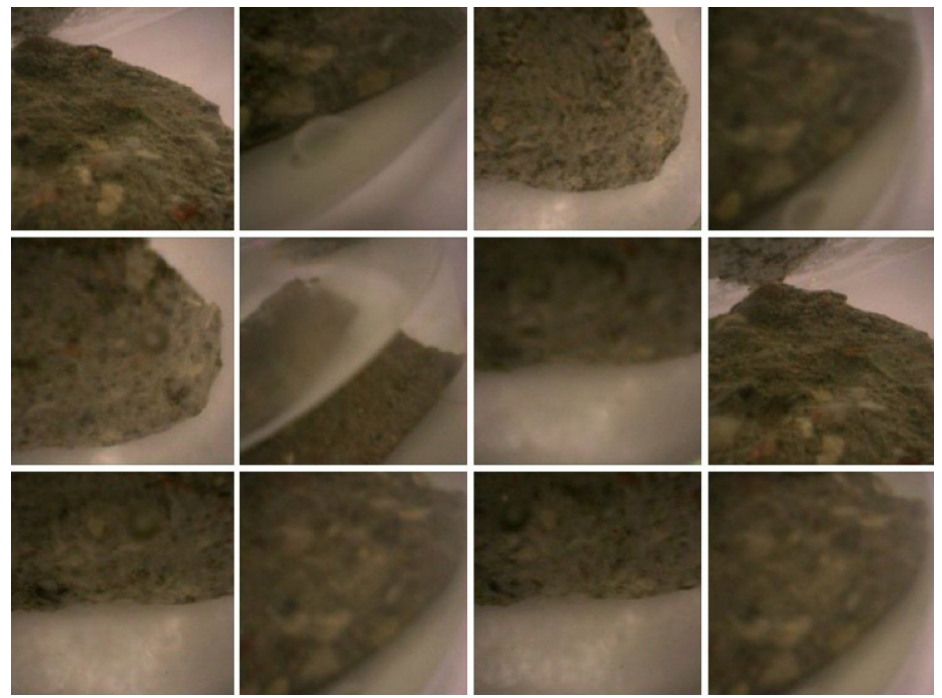

Figure 10.22: In the presence of concrete fragments, 'protopearl'-producing DEPP droplets were inclined to roll off the concrete and settle on the bottom of the container. Photographs and collage, Rachel Armstrong, February 2009.
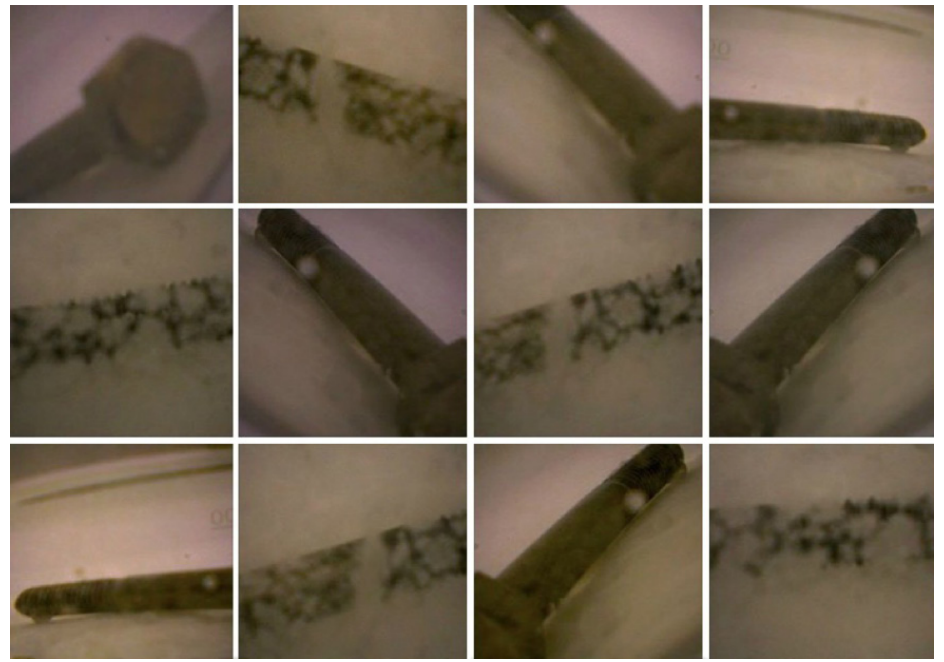

Figure 10.23: In the presence of a rusty bolt, 'protopearl'-producing DEPP droplets produced a significant flocculent precipitate, which was not confined to the oil/water interface. Photographs and collage, Rachel Armstrong, February 2009. 
in the presence of brick fragments. The DEPP droplets self-organized under the influence of gravity and then adapted to local conditions. In the case of the wood splinters, the presence of air in some of the fragments caused the droplets to move and occasionally become entangled with air bubbles that precipitated around the crystals before escaping to the surface of the water. The presence of contaminants in the building materials, such as dust, soil or rust, did not appear to affect the performance of the primary metabolism, except in the case of the brick fragments, where precipitation was reduced.

More specific, rigorous analysis is needed in terms of the selection of materials, how they mineralize in the presence of silica salts (sodium silicate) $)^{71}$ and what kind of chemical bonds are formed with protopearls. However, these initial sketches provide some rudimentary observations that may assist the further design of different ELT species and the subsequent development of experiments. As such, my experiments are initial forays and design experiments that require much further detailed, scientific exploration, technological development and analysis. Yet, given the proposed architectural challenge, the experimental findings indicate that in their current 'model' form protopearls have the potential to be developed into a chemically programmable accretion technology, although the currently demonstrator model system has many limitations, which are outlined below:

- Biomorphic crystal shells require a degree of alkalinity that is toxic to biological systems.

- DEPP droplets promote the formation of diffuse precipitates as the system reaches equilibrium, which causes sedimentation and is not desirable in terms of water quality or as a functional result of the droplet technology.

- More detailed titration of the basic salt concentrations, the amount of silica salt added and the range of alkalinity is needed to produce an optimized result using this system, and will form the basis of further investigations.

- The degree of spontaneous mineralization in lagoon water was not observed. Further experiments will need to be conducted to establish these baseline criteria.

- DEPP is used as a plastic softener with oestrogenic effects and is therefore not suitable for use in natural systems. A range of non-toxic oils need to be identified and their role as a potential accretion technology considered. Ideally, alternative carrier systems will possess a spectrum of densities so that they are active at different depths in the waterways.

- The addition of silicates using a slow-release system, such as another species of droplet, or even perhaps the effect that silica from diatoms may have on facilitating and regulating artificial shell growth, is another set of variables that require greater exploration and characterization.

71 Sodium silicate is also known as 'waterglass' and is used as the medium in which crystal gardens are grown. 
- A photosensitive metabolism was not experimentally explored, although the proposal is based on experimental findings conducted by Martin Hanczyc.

- Site-specific experiments may be scaled up in tanks before field studies are designed.

- Fieldwork must evaluate impacts on water and wildlife.

- Fieldwork will need containment, perhaps by using porous materials or filter papers that enable minerals to enter the experimental site but prevents droplets from leaving.

- Mathematical modelling of the system may help better understanding of the physics and chemistry and enable further oil/water chemistries to be developed that are less toxic than the current models used. Cellular automata that appear in Stephan Rafler’s 'continuous' version of John Conway's 'Game of Life' (Gardner, 1970), which uses floating point values instead of integers (Doctorow, 2012), shows some homologies with the Bütschli system. Computer modelling the Bütschli system, or another suitable species of dynamic droplet, may help to characterize the operational principles of the system and help to extend the range of possibilities for establishing transferable design principles for the production of artificially grown coastal reefs over a range of different sites, e.g. the Maldives or Songdo.

\subsection{Further Development of Dynamic Droplets}

The mineralization and structural processes that constitute the synthetic reef-like materials could be architecturally regarded as soft scaffolds. They may be further monitored and strategically influenced using morphological computing techniques by introducing distributed data collection systems into the most active sites of reef formation. For example, smart dust, which is a speculative technology still in development (Warneke et al, 2001), is made up of a population of small sensors with microprocessors and transmitters that may detect light, chemicals, vibration and temperature, and could work in a distributed manner to direct human agencies to respond to changes within the site as the reef is actively growing. Digital sensors and displays could be used by a community of experts that may include architects, ecologists, local historians and engineers to evaluate a range of parameters, such as the effect on the expanding reef on the buildings of Venice or its impact on native ecosystems. To the degree that they transform minerals and carbon dioxide to become an active accretion technology, the smart droplets could also serve as a pollution sequestration system that may even reduce sediment in the water. Moreover, smart droplets would reduce the acidity of the water as they remove carbon dioxide from solution and fix it into a solid substance. Yet, the most striking aspect in this context is that, working in concert with digital monitoring systems, dynamic droplets may be able to directly interact with their environment and respond to local changes in its chemistry. With the overall impact of the lagoon ecology and the welfare of the city 
in mind, decisions based on the information gathered from active sites could then be made to release new resources into the environment, or withhold certain droplet populations. Indeed, in many ways it is advantageous that the droplets do not possess the ability to spontaneously replicate with any vigour and rely on humans to feed and direct their macroscale operations. The appropriate technological governance of the different species of ELT could oversee the interacting systems and encourage them to grow in a particular direction, sequester specific compounds or secrete desirable products. The spatiality of the developing reef has synergies with embryological processes $^{72}$ and pattern formation that involve orchestration of complex material systems and unfolding manifolds of space and matter over time. These architectures do not propose an 'artificial' life, as in John Frazer's digital morphogenesis where Nature provides the model for generative forms (Frazer, 1995, p.9), but directly integrates with living processes as a fundamentally synthetic and material practice - as 'parallel' embryology (Lionni, 1977). ${ }^{73}$ During the formation of undulating folds of reef-like matter, smart droplets, marine biology and the environment sequentially position chemical gradients and other forms of 'soft control' to create organizing centres that may generate propagating waves of activity that attract, activate and inhibit interactions within the reef. Chemical cues could be delivered to site-specific locations throughout the city via modified cisternae that provide access to the terrain under the heart of Venice, which is not easily accessed from the periphery. The addition of specific substances such as calcium salts could augment the activity of droplets and marine organisms through seeping fields of chemical activity that surge like developmental waves. Depending on the timing and nature of these periodic, chemical signals, dynamic structures could evolve underneath the foundations of the city (see Fig. 10.24). ELT species could therefore provide a nexus for human influence in a technologically mediated ecological system, or post-natural fabric, by manipulating the chemistries and regular assessment of growth of the reef. In particular, indigenous marine life such as barnacles and clams may be encouraged to participate in the synthetic reef formation, for example, by manipulating the bioavailability of minerals, as they are naturally able to sequester carbon dioxide as mineralized forms and continually produce new niches for the local marine ecology.

72 In this context I am not referring to embryology as a formal style inspired by natural processes, as in Greg Lynn's ‘Embryological House’ (Lynn, 2000) where forms are barely (algorithmically) linked to their nutrient supplies. Rather, I am referring to embryology in a very literal sense - where selforganizing material systems are immersed in, saturated by and changed by their environment (yolk sac, placenta, water). The intimacy between conceptus and context codesigns the successive transformations of the matter in the system through many generations of iterative additive and subtractive processes.

73 I am intrigued by Lionni's notion of 'para-materiality' as a way of dealing with imaginary structures which are called into existence through a) direct and indirect observation and b) symbols. These tactics potentially offer ways of addressing the probabilistic nature of speculative design practices. 
With the appropriate level of surveillance, timely adjustments could be made where different species of droplet could be strategically designed and directed to produce a network of expanding subterranean canals that are centred on the woodpiles. With monitoring of the accretion process, marine ecologists could determine just how much fresh smart droplet solutions they need to add to the waterways to continue to 'fertilize' the biological accretion process and keep the reef alive. Alternatively, if the reef activity is too vigorous, then smart droplets may not be added to the water (via modified cisternae or directly into the canals), to slow down or even reverse the mineralization process. Ultimately, Venice's post-natural landscape will behave as a complex system that acts more like a living creature than a machine. Such a system would also need to be nourished and cared for, just in the same way that we might take care of our gardens. ELT species create the poetic notion of an architecture that connects a city to the natural world in a very direct and immediate way and even revitalizes it (see Fig. 10.25). A reef of this character would be porous, yet rigid, and could potentially stop the city sinking by producing an upward and lateral counterforce through the process of active growth, like expanding roots. With sufficient vigour, growth of the reef may even raise the city above sea level, although it is more likely to form laterally spreading masses that take the path of growth with least resistance.

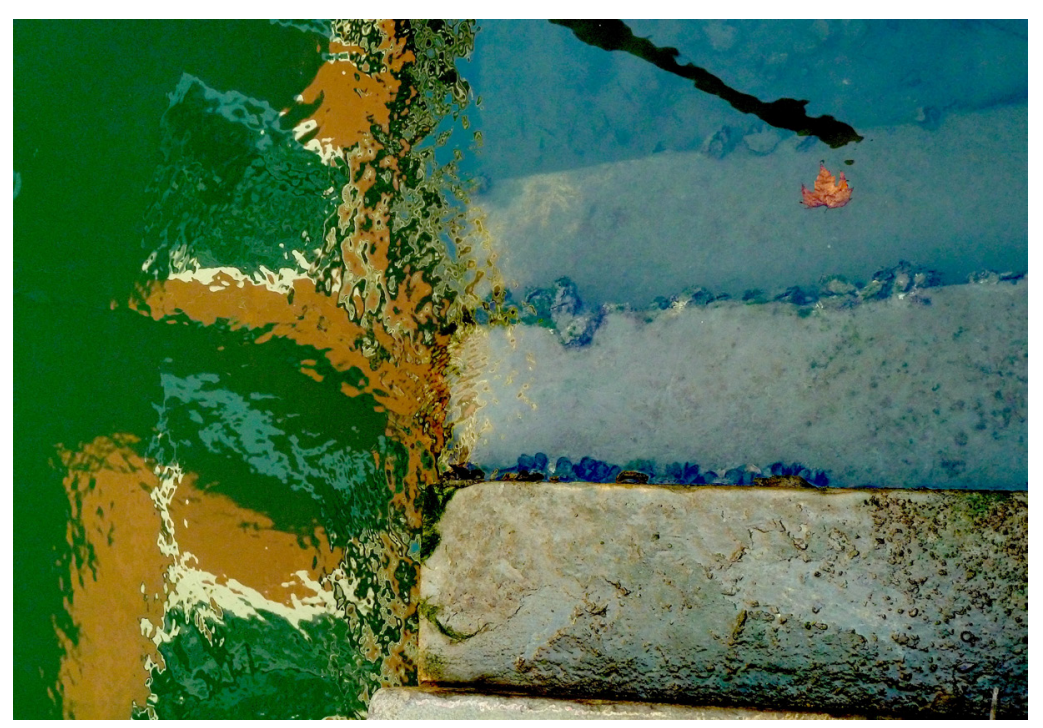

Figure 10.24: Reflections within the Venetian canals hint at a host of potential sites of transformation by ELT applications. Photograph, Rachel Armstrong, August 2012. 


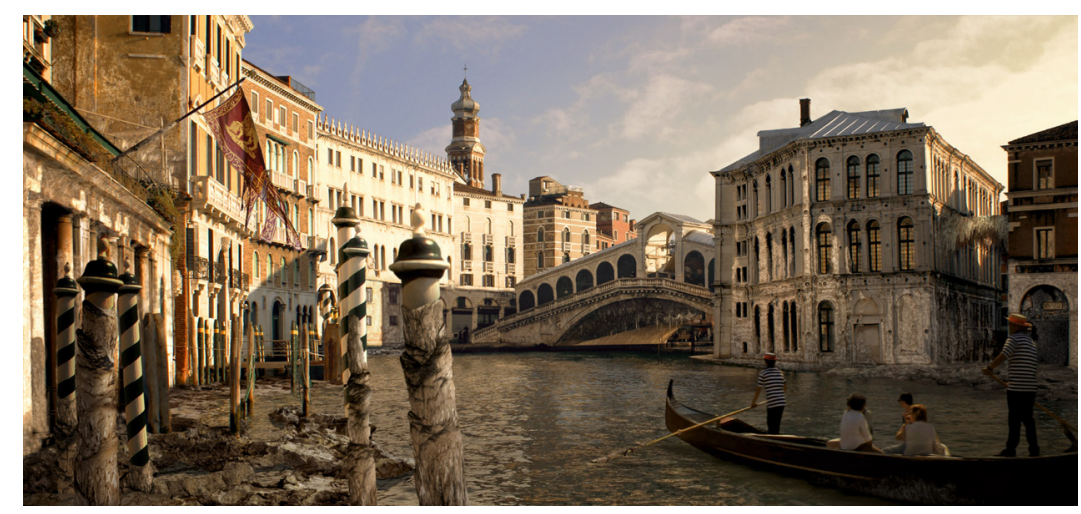

Figure 10.25: GMJ's rendering of a postcard from Venice transformed by dynamic droplets depicts a city that is transformed by self-organizing structures above the water level as well as underneath the foundations of the city. Drawing, GMJ, February 2009.

\subsection{ELT and Environmental Responsiveness}

According to Mr. Blainville, who usually is trustworthy, one can predict that in less than a hundred years will Venice be totally united with the rest of Italy and you can walk dry-shod from Italy to the city. (@Google, 2010)

But what if the trustworthy Mr Blainville is right, and Venice dries out rather than floods as a consequence of the raising of the MOSE gates causing an unpredicted tipping point in the lagoon? Or, perhaps Pietro Teatini and his colleagues will be successful in their modelling of anthropogenic lift of the city of Venice by a foot over ten years (Castelletto et al, 2008; Teatini et al, 2011) and begin a real-world project to reinflate Venice's aquifers with salt water.

ELT may respond to drastic changes and environmental tipping points by responding in real time to the changing environmental conditions, rather than trying to anticipate them (see Fig. 10.26). Programmable droplets are robust enough to reappropriate their interactions as conditions change. For example, should water levels recede, the ongoing mineralization of the reef would not be directed outwards to spread the point load of the city, but is likely to move inwards and downwards into the woodpiles. The vigorous chemical and biological activity is anticipated to produce a kind of bioconcrete accretion to protect the integrity of the woodpiles by sealing them from the air and preventing them from decay. The slower the water levels fall, the thicker the mineral coats would be. The biological-like accretion system of ELT offers a completely different kind of solution to Venice's exposed woodpiles, as an active ongoing repair process that would be able to reach sites that surveyors may find 
very difficult to discover or reach. In recent years, the city's foundations have been increasingly threatened by the passage of huge ocean liners that travel to the city and literally suck the water out from beneath it, exposing woodpiles that have previously been entirely submerged. Equipping Venice with a new set of properties such as those embodied in ELT would create a possible future for survival for the city, where its very fabric could respond directly to changing conditions, prevent regression into the soft delta soils on which it was founded and effectively engage in its own 'struggle' for survival, just like living systems do.

\subsection{Photographic Survey of the Biological 'Stones' of Venice}

During my research, I photographically surveyed the Venetian waterways using a Lumix Optica digital camera with $12 \times$ zoom lens. My survey identified the canals around the Arsenale as sites of rich assemblages of accretion-forming wildlife. The surveys revealed that the assemblages were most pronounced during April and May, while very limited formations were observed in December and January. The accretions were greatest between the low and high tidal areas and much less profuse deeper down in the water, although the water quality in the lagoon was poor and therefore hard to photographically survey.

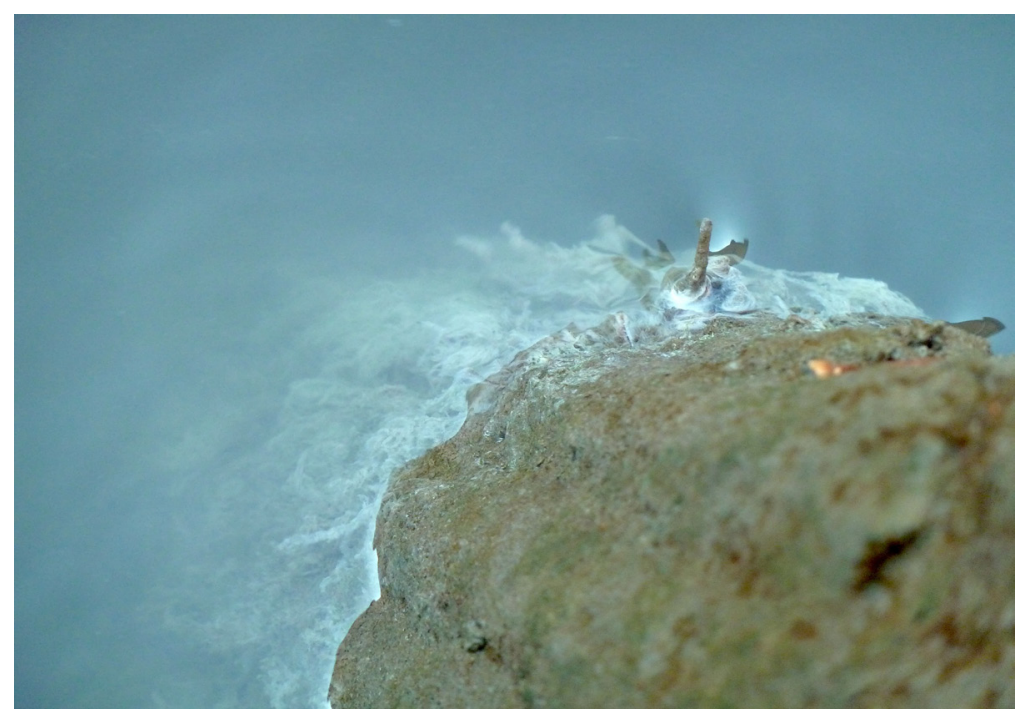

Figure 10.26: This mooring post is colonized by actants producing matter at the interface between air and water. Photograph, Rachel Armstrong, August 2012. 
Notably, shallows are also sites for naturally occurring stromatolites, such as in Shark Bay, Australia (Shark Bay World Heritage Area, 2009), which are mineral accretions grown by bacteria that may take hundreds - even thousands - of years to grow. During this survey, it became possible to imagine how an artificial reef could be constructed, working with the growth imperatives of the indigenous wildlife, yet facilitated by ELT, so that an effective reef that could spread the point load of the city, as well as provide a unique ecological niche, could potentially be grown within decades as opposed to centuries. While my photographic survey of the waterways revealed the mineralized stromatolite-like deposits of the native marine wildlife attached to the building fabric, the precipitates produced by the modified Bütschli droplets for the Hylozoic Ground installation are also suggestive of how a material solution produced by ELT may appear. I have made a speculative leap from what was actually observed around the Venetian waterways to practically integrating these ideas, through collaborative drawings made with Christian Kerrigan in Figs. 10.1510.17, which have been particularly useful in more widely facilitating discussions about applications of ELT within Venice's waterways. Kerrigan's time-based architectural drawings depict how a complex set of factors may interact and generate lifelike materials with unique aesthetics to produce a reef-like structure. They have also help identify points of possible influence within this process, such as encouraging the growth of stalagmites in the city as biotechnological 'stones' (Ruskin, 1989), or as a means of building up materials that have been digested by the acqua alta.

\subsection{Vibrant Venice: Weaving a Post-natural Fabric}

In speculating on the possible futures for the city, Vibrant Venice is one where lively matter shaped through ELT may forge an alternative development pathway that may be moulded by architects and citizens alike. This contrasts starkly with other proposals to 'save' Venice, such as the barrier against the tides afforded by the MOSE gates (United Nations Office for Disaster Risk Reduction, 2012), reinflating Venice's aquifers to raise the foundations of the city (Teatini et al, 2011), or constant repairs and maintenance after damage has occurred. Indeed, the bioregion of Venice may be considered as existing architecture that is embroidered by a constant proliferation of vibrant matter, which could be reconstructed by shaping spatial programs and tactics that generate new relationships between natural and artificial actants. The architectural inquiry concerns how overlapping spatial programs are fashioned and developing design tactics that enable a constant flux between fabric, space, structure and location. These are orchestrated through morphological computing outputs, which do not imitate Nature but work according to 'low-level' programming principles ${ }^{74}$ and

74 I am using the term 'low-level' chemical programming to refer to fundamental organic and inorganic chemical reactions that are unmediated by biological catalysts or DNA. 
the horizontal coupling between actants using a common chemical language. These networks, therefore, have the potential to constantly forge assemblages and respond to the constantly eroding and shifting bioregion.

The vision of Vibrant Venice provides an example of how incremental involvements and emergent dynamics might effectively work, through the production of life-bearing structures. By placing limestone shell creation in advance of the 'life' within those new shells before the evolution of soft-bodied organisms, the idea is suggested that architecture is not a secondary condition for 'life', but a primary driver. This implies that architecture itself may establish the conditions for the emergence of 'life', such as in the production of soils and water infrastructures. Rather than simply generating impermeable boundaries between systems, which characterizes the production of modern architecture, Vibrant Venice proposes that small, subtle events may radically transform the biological potency of a site so that it promotes rather than constrains 'life'. Through physical incursions of carbonate accretions, ELT collectively produces disruption within the complex marine foundations of the city of Venice and establishes a dynamic network of potential architectural events. These culminate in a reef-like formation that is codesigned by the marine wildlife and the city's inhabitants (see Fig. 10.27).

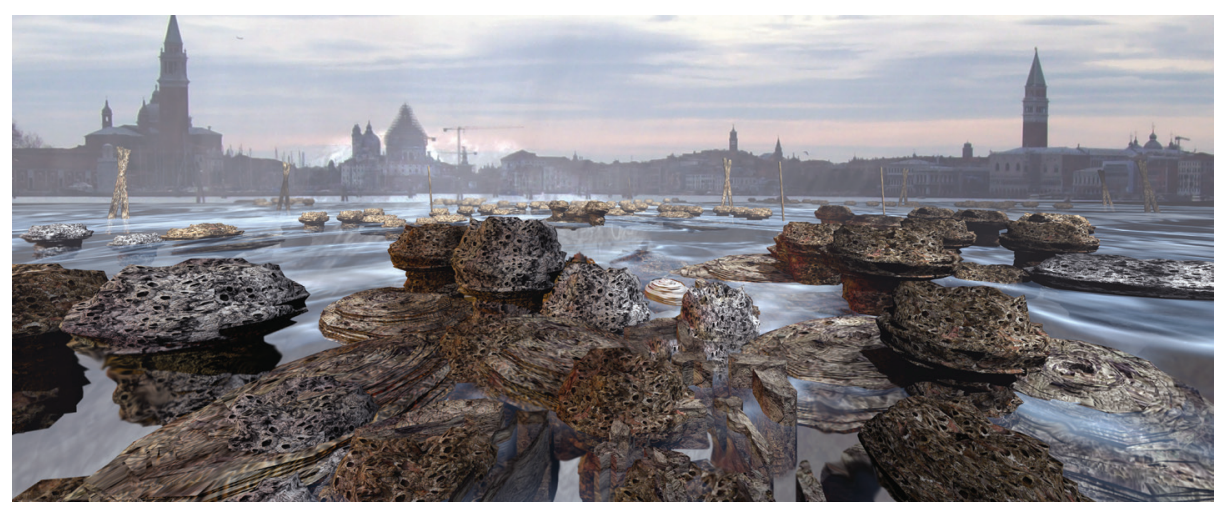

Figure 10.27: Stromatolite-like formations in the Venetian canals are shaped over time to produce mineralized materials. Computer drawing, Christian Kerrigan, September 2012.

As conditions in the lagoon change and the waters recede, a variety of ELT species may produce further richness in managing material and environmental complexity through a range of metabolisms and approaches. When combined, these actants may generate a portfolio of material responses, whose assemblages transform the city from being regarded as a passive object in its struggle for survival to an active participant in co-constructing its future (see Fig. 10.28). Through the strategic application of agile 
assemblages, orchestrated through ELT and shaped by morphological computing technologies, the city of Venice and its community could identify ways to deal with the constant change in their surroundings. Material networks may be established that could be orchestrated to restore, repair or even extend the city's fabric for its continued survival in the long term.

Yet, vibrant matter and ELT are more than functional material systems that build microstructures, but also possess the same kind of radical creativity (Kauffman, 2008, p.xi) that Nature does, producing rich patterns and metapatterns with unique aesthetics. While John Ruskin studied and documented the rich architecture of the buildings of Venice in detail (Ruskin, 1989) to formalize a classification system of construction and ornament, Vibrant Venice, as constructed by many species of ELT, could potentially offer a different kind of ornament and construction process. Such 'vibrant stones' would forge synthetic ecologies that reflect and continually respond to incessant changes at all scales (see Fig. 10.29).

They may be collectively regarded as a complex biotechnological system that exists as a range of assemblages, which are forged by the complex interactions between humans and non-humans. Vibrant stones share homologies with biogeological stromatolites, which are ancient layered stone structures made of calcium carbonate. Stromatolites are produced by the actions of photosynthetic cyanobacteria and other microbes, which trap and bind grains of coastal sediment into fine layers (Bernhard et al, 2013). Like stromatolites, the 'vibrant' stones of Venice also use biological and mineral actants to establish strategic connections and associations with their surroundings that change with time $\mathrm{e}^{75}$ and alter the architectural character of the city ${ }^{76}$ Venice's 'vibrant stones' may therefore change through the production of new relationships, which, in turn, alter their physical composition and appearance (Bennett, 2010, p.4). Perhaps similarly to Calvino's Marco Polo (Calvino, 1997), each visitor to Vibrant Venice may experience unique psychogeographies and improbable landscapes as the buildings become mirror images of themselves, or rise unexpectedly from the lagoon as alien landscapes.

Although different species of ELT are not alive and therefore cannot replicate, they do share lifelike qualities and are therefore capable of unpredictable behaviour (see Fig. 10.30). In keeping with the character of natural systems, ELT is also capable of novelty when tipping points are reached and strategies need to be in place that

75 It is thought that the stromatolites disappeared from global coastlines with the evolution of foraminifera, single-celled organisms that use slender projections called pseudopods to engulf prey, move and continually explore their immediate environment. Potentially, these creatures could be introduced into the canals as a living architectural design tactic to reshape the interactions of the stromatolite-forming communities so, instead of producing large, layered stones, they make clumpy, smaller structures called thrombolites (Bernhard et al, 2013)

76 In some ways, Palais Idéal may be thought of as a kind of thrombolite produced by humans, rather than bacteria and protists. 


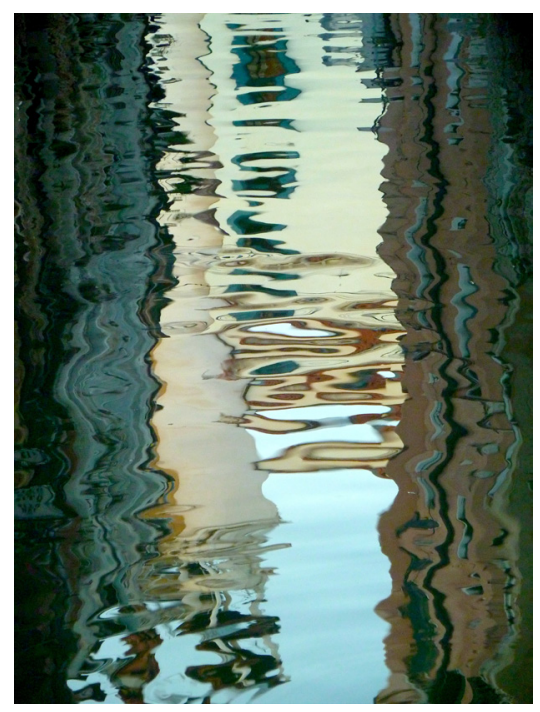

Figure 10.28: The constant flux between fabric, space, structure, time and location constitutes the transformative potential of assemblage-based technology. Photograph, Rachel Armstrong, August 2012.
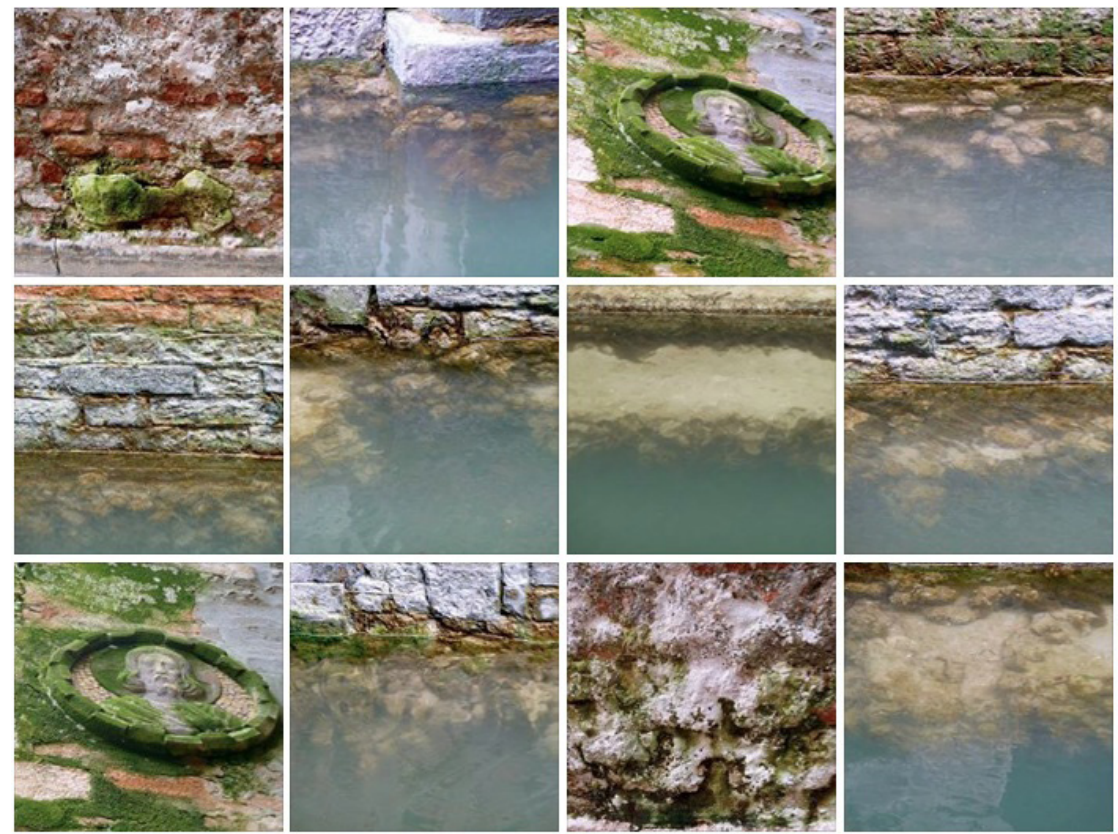

Figure 10.29: Green algae are ubiquitous in Venice and may be thought of as biological 'stones' that - unlike Ruskin's stones that alluded to Platonic forms - are vibrant processes that transform inert materials into synthetic ecologies. Photographs and collage, Rachel Armstrong, August 2012. 
are designed to deal with unexpected outcomes. Yet, the changeability of ELT does not mean that 'anything goes' but that the system's outputs exist within definable limits that are determined by the interactions between the agents and their surroundings. ELT enables us to establish new relationships with our ecosystems by becoming involved with their performance, rather than simply commanding them so they may be abandoned - which is what we do with machines. Yet, no matter how unusual ELT may seem, the different species are unlikely to produce something really alien. The vibrant stones of Venice will be gardened into existence, so much will already be understood about how to persuade and influence the outputs (Sellars, 2011). Yet, ELT represents the tip of an iceberg of opportunities provided by the technological potential embodied in living systems and possesses a remarkable range of distinctive useful properties, including autonomous activity, environmental sensitivity, robustness, spontaneous adaptation and material creativity (see Fig. 10.31).

Yet all these events are part of and intimately connected to Venice itself, as chemical poetry whose sonnets make reference to the natural world but do not succumb to naturalistic clichés. However, Vibrant Venice does not regard Nature as an untouchable inspiration to inform our endeavours but as a very real part of the everyday fabric, which operates within a different organizational framework than industrial systems. Yet, while industrial technologies may subordinate and poison the

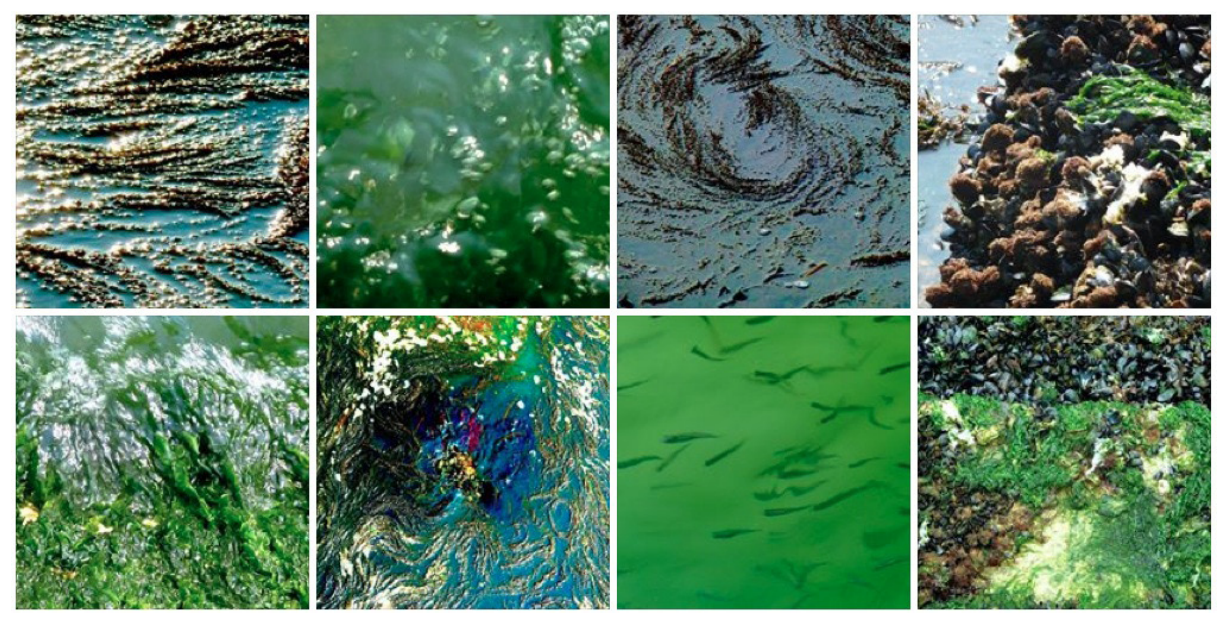

Figure 10.30: The various species of algae in Venice generate outputs that can be predicted within definable limits of probability, such as blooming. However, when these systems reach tipping points, the assemblage may also behave unpredictably by dying. Photographs and collage, Rachel Armstrong, August 2012. 


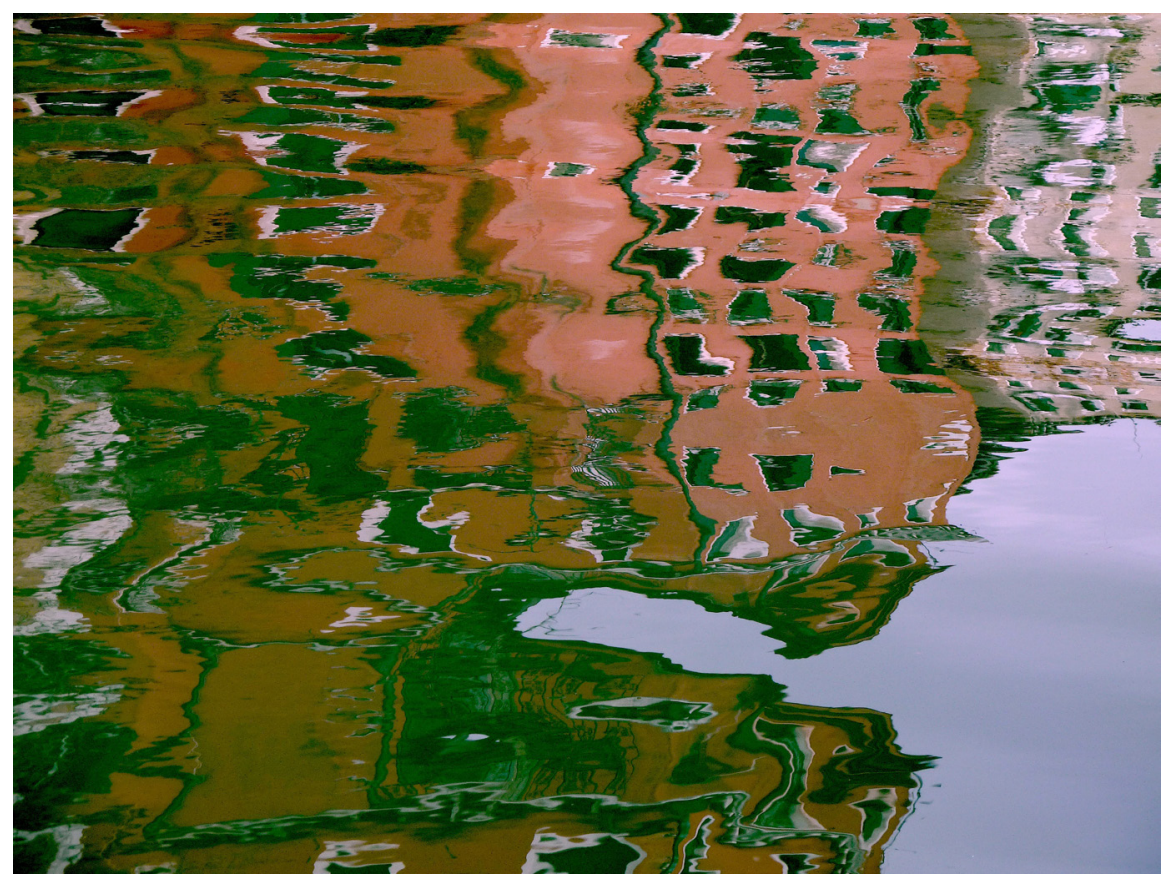

Figure 10.31: These reflections allude to the chemical poetry of Venice's fabric, which is shaped by countless acts of codesign. Photograph, Rachel Armstrong, August 2012.

natural world, out of control naturalistic material systems may be equally damaging for the city’s longevity (Sellars, 2011).

\subsection{Ethics, Control and Grey Goo}

This is the first moment in the history of our planet when any species, by its own voluntary actions, has become a danger to itself - as well as to vast numbers of others ... 'Plants' with 'leaves' no more efficient than today's solar cells could out-compete real plants, crowding the biosphere with an inedible foliage. Tough omnivorous 'bacteria' could out-compete real bacteria: They could spread like blowing pollen, replicate swiftly, and reduce the biosphere to dust in a matter of days. Dangerous replicators could easily be too tough, small, and rapidly spreading to stop - at least if we make no preparation. We have trouble enough controlling viruses and fruit flies. (Joy, 2000)

The idea of ELT raises questions about control, ethics, bioterrorism and dystopian grey-goo scenarios, which accompanied the advent of nanotechnology (Merkle, 1992), such as Bill Joy's online commentary about the combination of nanotechnology with genetic engineering (Joy, 2000). Although ELT is not fully alive and is created 
from non-living matter, it nonetheless raises a number of social and ethical issues. These range from impacts on individuals, society, health, waste processing and the environment to cultural challenges such as moral prohibitions, values and the understanding of Nature. These considerations are essential in establishing responsible new ways of working, as well as meeting the needs of human and nonhumans. In its current form, ELT is not fully alive and does not possess the chemical strategies that promote uncontrolled replication. For example, programmable droplets rely on the availability of dissolved carbon dioxide and minerals in the lagoon to construct a reef. Their actions are also dependent on the direction offered by chemical and physical languages in their environment such as concentration gradients and sunlight. Once their metabolism, or resources are spent, they cannot be refreshed; so, the welfare and proliferation of ELT is entirely dependent on infrastructure and environmental factors and, therefore, may be entirely shaped through appropriate design programs.

\begin{abstract}
The notion of an uncontrollable limestone reef that spreads like a malignant cancer underneath one of the world's most romantic cities is one that would delight science-fiction fans and horrify conservationists in equal measure. But Armstrong, a sci-fi author herself, is adamant that there is no real risk of it happening. 'We wouldn't just start throwing [proliferating] things into the lagoon. You wouldn't do it without any telemetry or measurement of the ecological impact, but we'd have done a lot of work to understand this before we ever did a Venice-sized intervention,' she says ... Armstrong recognises the potentially devastating effects of [ELT] falling into the wrong hands but 'You can't prevent people from being Machiavellian,' she says. 'I wouldn't be as blasé as to say there is no concern. I know that we need to design with our eyes open.' (Patel, 2011)
\end{abstract}

While the precautionary principle (Epstein, 1980) urges caution in the use of emerging technologies, there are also risks with not developing new approaches to underpin human development. The global impact of industrial technology is devastating our ecosystems and, although there is no risk-free solution, there are obvious possible strategies for coping with the risks in working with ELT. One is simply to limit their use to confined areas and not let them escape into the environment, which is a common approach to dealing with dangerous natural pathogens, such as the Ebola virus. Another method is to design ELT to self-destruct, or build in mechanisms that cripple or control it. Yet, since dynamic droplets, for example, are so chemically simple that they are unable to self-sustain, designing complex strategies to incapacitate them is unlikely to be cost-effective. A third approach is to programme the droplets to be dependent on a substance that can be blocked or which is normally unavailable in the environment, so that they can only persist in the presence of this particular 'food'. Yet, ELT has a strictly limited lifespan that is proportional to the availability of resources that feed its individual metabolisms. Consequently, it quickly becomes inactive unless the supply of these nutrients is strategically sustained. Quite frankly, the biggest challenge that ELT faces in the environment is engineering it with the ability 
to persist long enough to perform useful work. Further research and development of the technology is necessary to develop a formula that can be sustainable by adding 'food' to the lagoon in desired locations and to conduct controlled experiments to test its impact on the lagoon ecologies. Yet, such observations and measures would not placate concerns about the introduction of artificial agents into native ecologies, as all safeguards are fallible, costly and no containment method is perfect (Bedau and Parke, 2009).

As with all ethical dilemmas, there are no clear-cut answers to challenging questions and there is always a degree of risk associated with working in emerging practices that raise fundamental questions about our current expectations and practices. In my view, ELT is a field worth exploring, so that evidence-based operational principles, methods and practices may be developed that enable us to make informed decisions about their applications. Equally, an over-zealous application of the precautionary principle may be damaging if it prevents us from developing a range of approaches that could conceivably give rise to new paradigms that could underpin human development. Being too risk averse with the exploration and development of new technologies will, quite simply, leave ourselves with no alternative paradigms to industrialization from which to choose.

\subsection{Summary}

Contemporary cities are designed by making predictions about future challenges and then proposing fixed sets of structural solutions that deal with these eventualities. As such, they possess very little robustness or resilience in dealing with unpredictable events, such as natural disasters. With the prospect of increasing environmental turbulence as a consequence of climate change over the course of this century, a fundamentally different approach to the production of architecture is pressing. The prevalent industrial approach to urban development is fundamentally damaging to ecosystems, even when considerately applied using the principles of austerity and conservation, since these approaches have no regenerative value in the environmental health of the land they occupy (Friedlander, 2009). Vibrant Venice offers a specific context in which an alternative approach to architectural design may be explored using the technologies of 'life' to sustain and even nurture environments, by establishing new ecological networks and post-natural fabrics, which increase the fertility of the site.

Vibrant Venice also builds on the city's longstanding history of surviving the continual assault by the elements, in forging new relationships with cutting-edge technologies. Vibrant matter serves as a potential next technological platform in the city's development that could 'save' the historic site from destruction - not by creating a barrier against the elements (as in the case of the MOSE gates), but 
by undergoing many acts of orchestrated transformation (Dpr Barcelona, 2011). The combined speculative and experimental approach adopted in this proposal enables architects to embrace an emerging spectrum of ideas, methods, materials, infrastructures and technologies that are not mainstream approaches, but open up radical new possibilities within architectural design practice that may be nurtured into existence. As Riya Patel notes:

For architects and designers of infrastructure, it's hard to embrace a built proposition that doesn't involve concrete or steel but that's exactly what Armstrong is asking us to do. 'When we talk about systems in architecture, we tend to revert to machine iconography,' she says. 'With protocells, we don't need to. It doesn't have parts; it's not an object.' It may act more improbably and organically than any architecture we know, but it represents a chance to replace the outdated practice of designing buildings as environmental barriers with a more constructive and harmonious approach. (Patel, 2011)

A demonstration protopearl model of the proposed technology was built and tested in the field collaboration with chemist Hans Toftlund, Martin Hanczyc and architecture students from the University of Venice. Although protopearls are far from formalized as a mature technology, they experimentally demonstrated that vibrant matter:

- Possesses agency

- Is programmable using morphological computing techniques

- Is a codesigner of architectural programs

- Coherently operates across many scales that include the architectural realm

Much more rigorous scientific study for a real-world intervention is needed to develop the technology that would enable an artificial limestone-like reef to be grown under the city of Venice and will form the basis for future research. Yet, in the near term, it is likely that dynamic droplets and other species of ELT may work alongside traditional materials and mechanical systems in other contexts at smaller scales, such as in 3D printing (University of Southampton, not dated; WETFab, 2011, Armstrong, 2012g; Adams, 2012; Villar, Graham and Bayley, 2013), or 4D printing technologies (TED. com, 2013b), where they may be integrated within a combined platform of material, infrastructure and technological systems that enable new methods of production for architectural practice (see Fig. 10.32).

Yet, vibrant matter does not propose a comprehensive solution to Venice's precarious future, or act as an antidote to change. Rather, it increases our portfolio of choices to deal with the instabilities of our reality. Vibrant Venice is, therefore, not just a laboratory for examining the potential impacts of an emerging technology but is also a real and imaginary stage where common international issues - such as changing cultural, environmental, economic and political conditions - may be played out in full view of global audiences (see Fig. 10.33). While my research does not propose to exhaustively debate the ethical challenges of working with lifelike 


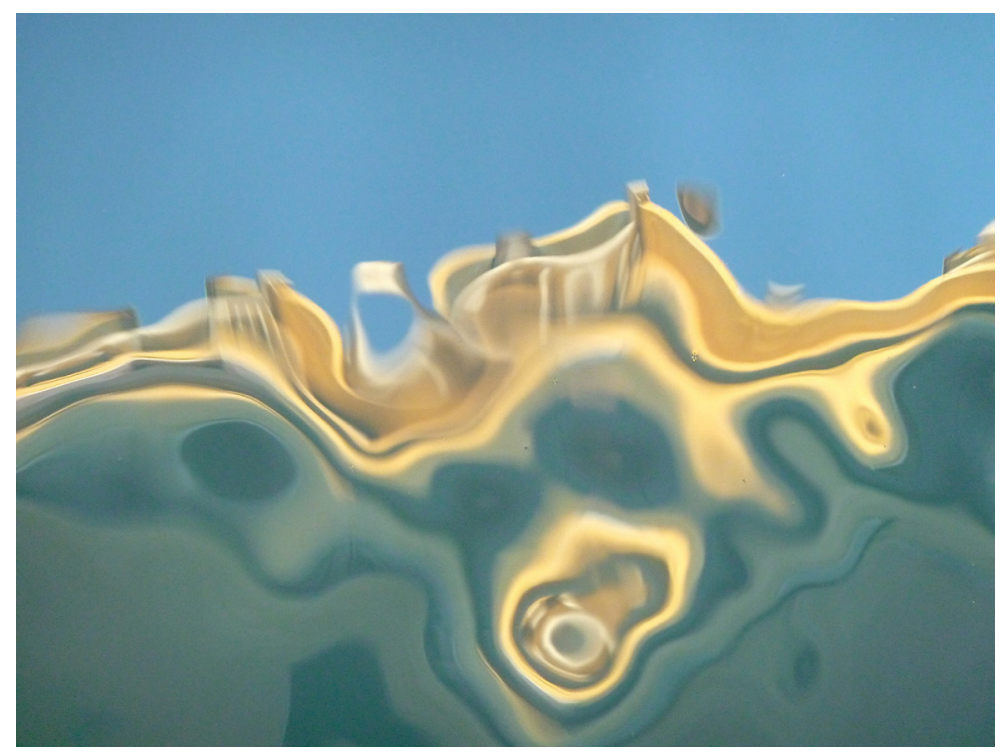

Figure 10.32: Waterway reflections provide a sensor and fabric that betrays some of the complexity of ELT applications, which offer a combined platform of material, infrastructure and technology that may inform and enable new kinds of architectural practices. Photograph, Rachel Armstrong, August 2012.

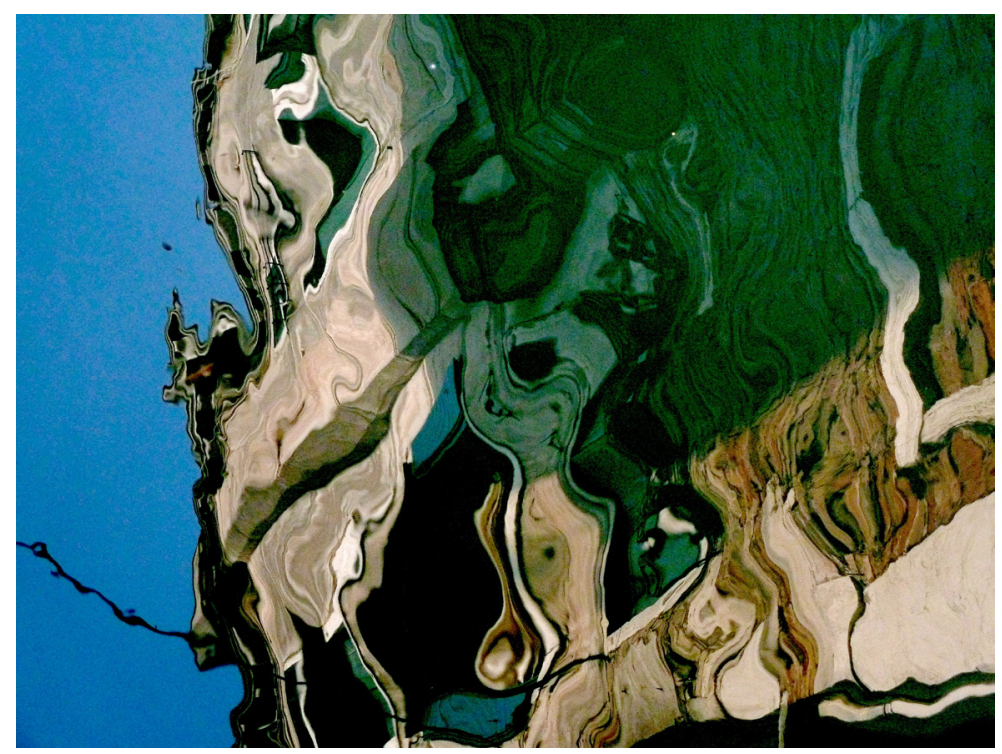

Figure 10.33: This waterway reflection speaks of the longstanding codesignership of Venice by human and non-human agents. Photograph, Rachel Armstrong, August 2012. 
technological systems, the next chapter uses speculative fiction to consider how a thriving future for the city may evolve from the complex interactions and possibilities between different species of ELT, native ecologies, garbage and human culture in the bioregion of Venice. 